\title{
The Impact of Social Media Use on Consumers' Restaurant Consumption Experiences: A Qualitative Study
}

\author{
Jooyoung Hwang ${ }^{1, *}$, Anita Eves ${ }^{2}{ }^{(D}$ and Jason L. Stienmetz ${ }^{3}$ \\ 1 Department of Tourism and Convention, Pusan National University, Busan 46241, Korea \\ 2 School of Hospitality and Tourism Management, University of Surrey, Guildford GU2 7XH, UK; \\ a.eves@surrey.ac.uk \\ 3 Department of Tourism and Service Management, MODUL University, Vienna 1190, Austria; \\ jason.stienmetz@modul.ac.at \\ * Correspondence: love82jy@naver.com
}

check for updates

Citation: Hwang, J.; Eves, A.; Stienmetz, J.L. The Impact of Social Media Use on Consumers' Restaurant Consumption Experiences: A Qualitative Study. Sustainability 2021, 13, 6581. https://doi.org/10.3390/ su13126581

Academic Editor: Jose Ramon Saura

Received: 7 April 2021

Accepted: 31 May 2021

Published: 9 June 2021

Publisher's Note: MDPI stays neutral with regard to jurisdictional claims in published maps and institutional affiliations.

Copyright: (c) 2021 by the authors. Licensee MDPI, Basel, Switzerland. This article is an open access article distributed under the terms and conditions of the Creative Commons Attribution (CC BY) license (https:// creativecommons.org/licenses/by/ $4.0 /)$.

\begin{abstract}
Travellers have high standards and regard restaurants as important travel attributes. In the tourism and hospitality industry, the use of developed tools (e.g., smartphones and location-based tablets) has been popularised as a way for travellers to easily search for information and to book venues. Qualitative research using semi-structured interviews based on the face-to-face approach was adopted for this study to examine how consumers' restaurant selection processes are performed with the utilisation of social media on smartphones. Then, thematic analysis was adopted. The findings of this research show that the adoption of social media on smartphones is positively related with consumers' gratification. More specifically, when consumers regard that process, content and social gratification are satisfied, their intention to adopt social media is fulfilled. It is suggested by this study that consumers' restaurant decision-making process needs to be understood, as each stage of the decision-making process is not independent; all the stages of the restaurant selection process are organically connected and influence one another.
\end{abstract}

Keywords: restaurants; decision-making process; smart phones; social media; consumer behaviours

\section{Introduction}

The consumer decision-making process has been studied by a large number of previous researchers [1,2]. However, there are few studies that examine consumers' decisionmaking process when selecting a restaurant. Most literature reports on the factors influencing consumers' decisions; food quality, service quality, price and food provenance have been identified as important determinants in these studies [3-7]. However, previous studies were conducted using a quantitative research approach, and deeper insights into consumers' restaurant decision processes and consumption experiences are still needed, particularly as mobile technology and social media becomes increasingly engrained into modern society. For example, a survey conducted by Restaurant Insights [8] found that $68 \%$ of restaurant-goers in the US visited a restaurant they had never been to before based entirely on positive reviews on social media. Nielson [9] reported that the number of people who use mobile phones to search for information about restaurants is double that of individuals searching for travel and that people tend to perform mobile restaurant-related searches across all consumption stages (at home, on the go and in restaurants). Clearly, consumers' IT tool usage will continue to have an increasing role in dining choice processes (e.g., information searching, sharing content, communicating with others, etc.). The current environment is constantly changing, and the representative issues surrounding the tourism and hospitality industries are technological development and environmental change [10]. It is now well known that destination setting and decision-making by tourists and consumers cannot easily occur without the use of interactive media such as smartphones and social media [11,12]. It seems that smart tourism also plays a clear role in determining 
the sustainability of the tourism industry by setting destinations, examining other guests' reviews and making decisions based on these influences. As an area of smart tourism, the process of using smartphones and social media to determine restaurants to visit is not just a one-off experience but a valuable study that directs development in the ever-growing smart tourism, hospitality and restaurant industries.

Therefore, this study aims to explore the impact of social media use of smartphones on consumers' restaurant experiences. The specific research questions of this study are to (1) examine the key factors related to adopting social media on smartphones for restaurant decision making and the usefulness of social media use on smartphones for restaurant selection and (2) investigate how consumers utilise social media on smartphones for their restaurant experience in accordance with the different consumption stages (before, during and after visiting a restaurant). Through answering these research questions, it is expected that the findings of the current research will offer practical implications for stakeholders in the tourism and hospitality industry to develop effective social media marketing. In addition, restaurant practitioners can be advised how to manage consumer comments about their restaurant experiences.

\section{Literature Review}

\subsection{Consumer's Decision-Making Process}

Consumers' decision-making processes normally start by recognising a problem or a need for a product, service or experience and then searching for information to inform their purchase [13]. According to Crotts (1999), consumers have to make many decisions when purchasing products during their lifetime [14]. Hence, consumer decision making has been of great interest to researchers for more than 50 years [15-17]. In terms of consumers' decision-making processes in the service sector, most of the previous literature has focused on identifying unique characteristics of services (i.e., intangibility, inseparability, heterogeneity and perishability) compared to the features of goods [18]. It has been suggested that attention should be paid to consumers' information search behaviours in order to fully understand and anticipate consumers' decision-making processes in the service sector, because the atmosphere in which consumers make a decision in the service sector is different from the product sectors $[19,20]$. That is, consumers' information search behaviours are more important in the service sector (including the restaurant sector) than in the product sector because of the characteristic uncertainty and intangibility of services [21,22]. Based upon this notion, consumers' decision-making processes in the restaurant industry should be examined with an approach that is different from the product sector so as to correctly understand how consumers behave when selecting a restaurant.

\subsection{Consumers' Restaurant Decision Making and Experiences}

Previous researchers investigating consumer decision making in the restaurant sector have explored various aspects in recent decades (e.g., factors affecting consumers' restaurant selection [3,6,23-25], motivational factors affecting consumers' beverage and food choice $[5,26,27]$ and the effect of ICT on the selection of restaurants [28,29]). A wide range of attributes have been identified, such as pricing strategy [23], the location of a restaurant [24], food type and food quality [3] and service and/or product quality [28]. Kim et al. (2009) examined the motivational factors affecting travellers' consumption of local beverages and food [26]. Mozeik et al. (2009) examined consumers' acceptance of restaurant e-services (e.g., booking online, online menu) across two types of computing devices: conventional laptop/desktop devices and mobile handheld devices [29]. Previous research has shown that travellers perceive restaurant decisions as the most flexible task within various travel facets [30]. This suggests restaurant decisions may be more easily affected by information acquired through the search process as well as other factors. In comparison with other service/product decisions in the hospitality industry (i.e., accommodation and travel destinations), restaurant decisions are deemed less risky in terms of time and distance; normally, decisions regarding a restaurant are limited to a one-off occasion, which implies that the 
consumers' mindset may be different from other decisions within the hospitality sector [30]. In other words, it can be argued that restaurant decision makers have a smaller decision opportunity cost than a consumer who has to decide on a more costly travel destination or accommodation.

On the other hand, regarding restaurant choice processes, there have been limited studies examining group decision-making processes, though group restaurant decision making is regarded as a common phenomenon these days. Most previous research regarding group decision making in the restaurant industry has investigated the factors that influence family / group restaurant decision-making; a relatively limited number of studies have examined restaurant decision making among non-family group members, which is regarded as a research gap. For instance, Labrecque and Ricard (2001) tried to measure children's and parents' perceptions of children's influence on the decision-making process for a family dining-out occasion and identified that children tend to underestimate their influence on dining-out decisions [31]. In addition, Seo and Yoon (2011) focused on identifying the influence of family type on family dining decisions between fast food and casual dining restaurants [32]. The results of the study indicated that family type is a significant factor in choosing a restaurant, but a child's age is more influential than family type. Also, child gender is the discriminating determinant for fast-food restaurants but not for casual dining restaurants. Chen et al. (2013) also investigated the influence of children in the selection of family group dining-out decisions and identified that children are an influential factor in the decision-making stages when deciding on the type of restaurant, the specific restaurant and the ordering of food [33]. However, there are many chances to study group restaurant decision-making processes in reality, especially in the digitalised environment in which restaurant decision makers can acquire a lot of information from technologically developed platforms. Thus, more studies are needed to examine restaurant decision-making processes among non-family group members.

Based upon previous studies, a number of researchers have explored a consumer's restaurant choice and their experiences. However, most previous studies are associated with certain research subjects (e.g., determinants of restaurant choice and family's diningout decisions) and are based on a quantitative research approach, which shows that there is still a theoretical gap regarding consumers' restaurant decision-making processes. In addition, previous research is more focused on which factors influence consumers' dining experiences rather than observing what comprises consumers' decision-making process. Thus, more specifically, there is a need to explore in depth how and why consumers restaurant-related decisions are performed, in accordance with their different consumption stages; this is a part of the research questions of this study. In addition, how the digital era could affect consumers' decision-making processes and restaurant dining experiences should be explored with the wide expansion of technology-based tools. Along with characteristics of restaurant choices (e.g., more flexible task and less complex decision), consumers have relatively high levels of uncertainty in their choices regarding restaurants compared to purchasing products. Therefore, consumers are more likely to be involved in searching for information to reduce the perceived risk of their decisions; they keep open the option to change their decisions according to the context they face, such as information obtained from external sources, rather than adhering to the initial planned decision $[34,35]$. In addition, current consumers can freely share and upload their restaurant consuming experiences with others, utilising developed mobile tools [36-38]. Accordingly, this study asserts that consumers' restaurant decision-making processes can be flexibly changed and affected by what they utilise for selecting a restaurant (e.g., information technology and developed mobile tools). 


\subsection{The Impact of Using Social Media on Smartphones on Consumers' Restaurant Decision Making}

The popularity of the Internet has reshaped the way consumers search for, collect and exchange information as well as purchase products and services [39]. Internet applications have reduced the cost and time for information research [40], and within the tourism and hospitality industry, consumers now tend to use the Internet for their decision making rather than using traditional booking methods (e.g., making phone calls, visiting venues to make a reservation) [41], because they can easily acquire travel-related information and use online transaction opportunities [42]. For instance, according to the research by BRP Consulting (2019), 39\% of respondents replied that their dining experiences involve smartphone or mobile devices (from making initial restaurant decisions to sharing restaurant experiences), which shows that smartphones, as one tool that enables people to utilise information technology regardless of time and place, comprise a large proportion of some consumers information search behaviours [43]. Utilising a smartphone anywhere and at any time can change consumers' decision-making processes when choosing a restaurant, and a restaurant choice may be changed depending on information obtained during the whole purchasing process via a technology platform. In the tourism and hospitality industry, social media has been adopted by travellers to search for information, organise travel, share experiences and annotate their travel stories and their own experiences through various channels: blogs, online communities, media sharing sites, social knowledge sharing sites and other tools [44]. Many previous researchers have examined consumers' use of social media in the tourism and hospitality sectors [44-49]. For instance, Wang and Fesenmaier (2004) proposed that social media is useful for managing consumer relations because it can attract consumers through unique features such as detailed, attentive and user-generated content [46]. With the features that social media provides, practitioners in the industry can engage with consumers through social interactions and also maintain consumers by building relations with other members. Thus, this study implies that it is essential for the tourism and hospitality industry to use social media to manage the relationship with consumers. Moreover, Dellarocas (2003) illustrated that utilising social media can provide tourism companies and practitioners with chances to understand what current consumers want and to respond to customer preferences [45]. For instance, by analysing comments on online communities such as TripAdvisor, hotels and other travel-related companies, businesses can gain a better understanding of consumers' real thoughts regarding their product. Furthermore, social media helps to engage potential guests, increase the online presence of tourism and hospitality companies, and improve online revenues through utilising user-generated content [44].

For consumers, social media is a matchless platform on which users can share their own experiences and thoughts online in various forms, such as text, photographs and videos via social networking sites, online review sites, blogs and media sharing sites [48]. In addition, social media enables consumers to share their decisions and give/receive instant reactions and acknowledgement [50]. Moreover, numerous hotels and tourism companies have exploited social media applications to enhance customer convenience in the search for travel information [47]. For instance, consumers can refer to realistic reviews about various kinds of hotels on social media applications. Moreover, hotel practitioners can leave comments, which can be helpful for them to deal with consumer inquiries in real time. With these features, social media has a strong potential to affect consumers' decision-making processes, especially in the tourism and hospitality sector. Researchers have found that consumers' decision making when selecting a restaurant commonly relies on online reviews provided by actual customers for acquiring information [51]. Given the above, there have been a large number of studies on the adoption of IT tools in the tourism and hospitality sector. However, there are still few studies regarding consumers' utilisation of IT tools/applications for their dining selection, regardless of their wide utilisation in consumers' everyday lives. It has been identified that social media is regarded as the top channel in which US restaurateurs have invested in marketing [52], which 
shows the importance of social media to the restaurant industry. Therefore, this study aims to explore the impact of social media use on smartphones for consumers' restaurant decision-making processes.

Consumers in the tourism and hospitality sector show different patterns of using IT and/or social media according to the stage of product/service consumption. The consumption of consumers in the hospitality and tourism industry can be organized into three categories: pre-consumption, during consumption and post-consumption [53]. However, consumers' behaviours cannot be exactly divided into a specific stage, because some decision-making behaviours when using IT/social media can occur not just at one stage but also at two or three stages of consumption simultaneously. In addition, the impact of IT/social media use according to different consumption stages may be different. In accordance with the pre-consumption stage, consumers' information search could be the first stage in the online decision-making process, as people who identify their needs are more likely to start searching for information [54]. Current customers who make a decision online have easy access to other users' opinions and experiences on the web (e.g., online forums, online review sites), which can influence consumers' entire decision-making process. With the characteristics of services in the tourism and hospitality industry (i.e., intangibility and perishability), it is not easy for consumers to assume the quality and perceived benefits of the services before they actually consume the selected services $[44,55]$. Technology can create new opportunities for social interaction of consumers who are at the during-consumption stage [56]. In terms of travellers who are in tourist destinations, technology may allow them to be more actively engaged with content that is personalised according to their needs. That is, there is a good chance that consumers who have decided on a restaurant are more likely to change their mind based on what information they acquired on social media during consumption, which means that consumers can still be affected by other consumers' reviews and might order different food even if they had already decided what to order. Therefore, this study involves a different conception; the during-consumption stage means that real consumption is made in the tourism and hospitality industry, but this study defines it as the 'stage during a visit to a restaurant'. Several previous researchers have examined consumers' social media usage at the post-consumption stage, as they believed that the post-consumption stage could provide different impacts of utilising social media compared to the stages of pre-consumption and during consumption. For instance, Fotis et al. (2011) identified that travellers who gained travel- related information through the Internet predominantly utilised social media after their holidays in order to share experiences and thoughts about their holiday destinations, accommodation or restaurants [57]. In addition, it has been identified that consumers post content related to their real experiences on social media in order to share their life experiences with others through social media and acquire social interaction through their behaviours of utilising social media [58].

Based on the previous literature regarding consumers' social media usage, it is assumed that individuals utilise social media with different purposes, and its impact is also affected according to the stage of consumption. As seen above, a number of studies have focused on finding the impact and role of user-generated content in travel-related decisions. It is expected that consumers' different activities across the different stages can be applied to the situation in which consumers make a restaurant decision. However, it is regarded that less research has explored consumers' social media use when deciding on a restaurant, and this can be considered as a research gap. Therefore, the research questions of this study are fixed as follows:

RQ1: What are the key factors related to adopting social media and the usefulness of social media on smartphones for restaurant selection?

$\mathrm{RQ2}$ : What is the deep insight about experiences regarding restaurant decision-making processes across all consumption stages? 


\subsection{Uses and Gratification Theory}

Although there have been many previous studies explaining why consumers adopt various forms of technology for consumers' decision-making behaviours (e.g., [59-62]), there is a need to find a theory that explains why consumers adopt social media for decision-making processes. The current study decided to adopt the uses and gratification theory [63], as the U\&G theory provides three dimensions of gratification-process gratification, content gratification and social gratification - that could be suitable for explaining consumers' social media adoption for their restaurant decision-making process based on the following reasons. First, recent restaurant consumers are regarded as more powerful and goal-directed about their decision-making behaviours, especially in the online environment $[64,65]$; thus, this study requires a theory satisfying both decision-makers' social and psychological purposes for examining the key factors related to consumers' social media adoption. Second, consumers' restaurant decisions are not just associated with consuming food but also related to consumers' total restaurant experiences across the three stages of visiting a restaurant.

Kayahara and Wellman (2007), who studied U\&G theory previously, have categorised media gratifications into two groups: process and content [66]. On the one hand, process gratifications are based on the performance of the activity, including Web browsing or making content on one's profile section. In their study of process gratification, Papacharissi and Rubin (2000) found that social media adoption and usage can provide convenience and usefulness to individuals [67]. The speedy exchange of information between social media users has been regarded as one of the useful features of adopting social media [68]. In addition, Shao (2009) mentioned that two factors, including "ease of use" and "let users control", can be regarded as usability attributes of user-generated media [69]. Lastly, Brown and Chalmers (2003) identified that consumers can easily access information that they need through developed technology, such as the Internet, smartphones and tablets [70]. Thus, the factors suggested by previous researchers can be regarded as attributes affecting process gratification. Unlike process gratification, content gratification arises from acquiring information [66]. For example, Kim et al. (2013) found that consumers are satisfied with the use of social media, as detailed and exact information can be provided by social media for their communication process [71]. As another attribute affecting content gratification with regard to the use of social media, Wang and Fesenmaier (2004) identified that trustworthiness between the individuals who want to contribute interesting information can be as useful as the knowledge obtained from each user or creator of information [46]. In addition, Baran and Davis (1995) asserted that media users follow their interests and choose media content in accordance with their needs; furthermore, they combine the content to satisfy those needs [72]. For example, Sigala (2012) found that current consumers utilise social media to identify new market trends, as they regard that social media can be helpful for satisfying their needs regarding finding out trendy and popular information [73]. Furthermore, Ramanathan et al. (2017) insisted that the role and usage of social media are related to enhancing consumer satisfaction, and it was identified by their study that online reviews on social media could positively affect customer satisfaction [74]. Therefore, it can be assumed that media users' selection and usage of media are goal-directed, purposive and inspired behaviours [75]. Based on the above literature, various previous researchers have applied the U\&G theory (Figure 1) to many kinds of non-traditional media, such as e-mail, mobile phones and the Internet (e.g., [76-78]), which implies the importance of consumers' media use. In addition, the $U \& G$ theory supposes that the active audience is selecting and making their own choices [79]. Furthermore, Quan-Haase and Young (2010) employed the $U \& G$ theory for their study to explain why university students utilise Facebook, as one example of social media, showing that users of the Internet, smartphones and social media can be assumed to be active audiences [80]. Consequently, these gratifications can be considered usual motives for consumers' various activities on social media. Based on previous studies' adoption and explanation as to why uses and gratification theory is appropriate, the current research considers that adoption of $U \& G$ theory could be suitable 
for explaining consumers' social media adoption for their restaurant decision-making process on the following grounds. First, current restaurant consumers are regarded as more goal-directed and active in what they are deciding; thus, the selection of the media they adopt is also related to their purposes, which are both psychological and social. Thus, the adoption of the uses and gratification theory can be appropriate for understanding current consumers' media selection and its usefulness. Second, there are many kinds of media that consumers can choose for their decision-making process in the changing environment. Last, it is regarded that restaurant decisions are not just associated with consuming food but related with total restaurant experience across the three different stages. Therefore, a theory explaining restaurant consumers' multiple motivations to adopt social media for decision-making is needed for the current study, and U\&G theory can fulfill this job with the three dimensions of gratification (i.e., process, content and social gratification). Despite the strengths of $U \& G$ theory, it has some limitations. For instance, this theory only takes into account the individual gratification derived from individual media use [81]. In addition, there is a possibility that consumers' media motivation/usefulness of adopting media cannot be fully explained by the three categorisations.

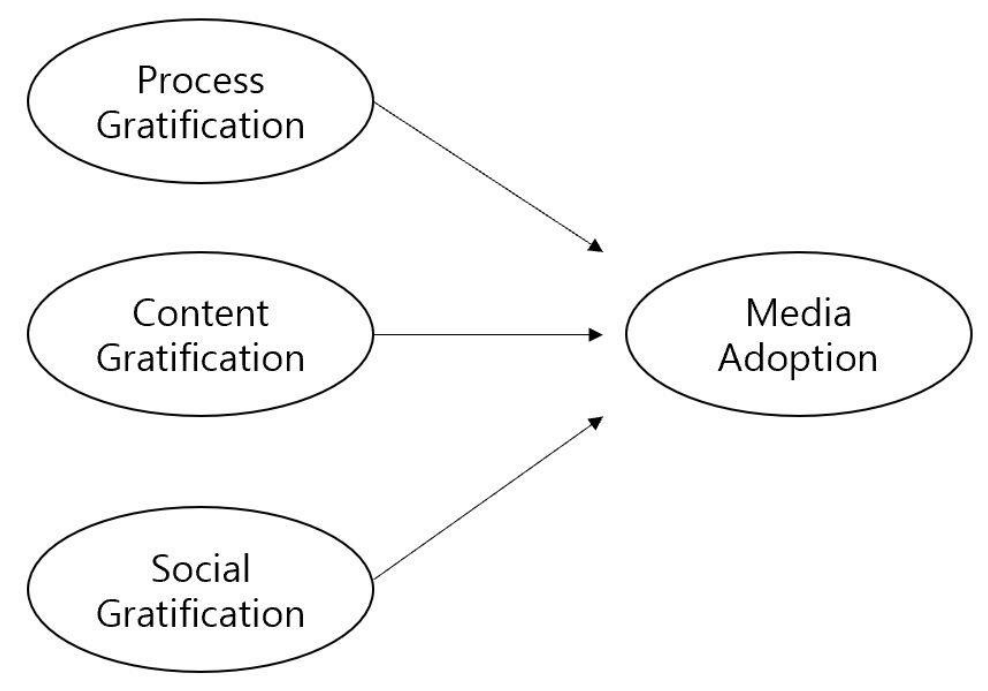

Figure 1. Determinants of the uses and gratifications of the Internet. Source: Adapted from Stafford, Stafford and Schkade (2004, p. 273).

Therefore, the U\&G theory, which provides the three dimensions of gratification-process gratification, content gratification and social gratification-is regarded as appropriate for the current study (see Figure 1). In this study, it is regarded that process gratification refers to users' satisfaction with the experience of the actual use of the medium itself, and content gratification refers to users' satisfaction with the ability of a medium to convey messages [82]. In addition, social gratification refers to the ability to communicate with other users by utilising the medium and is related to the fulfillment of social expectation [63]. Moreover, this study regards that the uses and gratification theory was developed based on the notion that consumers intentionally select certain media to fulfill their needs, which can justify the adoption of the theory for this study, as current restaurant consumers are expected to choose and utilise a type of media for their decision-making process in accordance with their purposes and motivations.

Through reviewing the previous literature, it was identified that less research has focused on how consumers are utilising social media in their restaurant decision-making processes, and there is a theoretical gap in understanding the underlying usage behaviours of advanced technology and its usefulness for restaurant decision-making processes. In addition, there are still a limited number of studies regarding consumers' utilisation of IT tools/applications for their dining selection, regardless of their wide utilisation in consumers' everyday lives. Moreover, there is still no adequate academic research on the 
role and impact of social media as a whole throughout the restaurant decision-making process. Therefore, the main aim of this study is to fill the research gap by exploring the impact and role of social media use on consumers' restaurant decision-making processes and understanding how this is manifested in the restaurant sector. There have been numerous studies on understanding restaurant decision-making behaviours that have focused on identifying the factors influencing restaurant choice in terms of individual and restaurant-related attributes [83]. Current consumers, however, are more likely to use information technology when choosing a restaurant. The consumers' restaurant choice can change depending on the information obtained during the purchasing process, implying increased chances of affecting consumer behaviours by offering personalised information via the proper technology platform. Consequently, this research is expected to offer deeper insight into the tourism and hospitality sector with regard to mobile information searches and restaurant decision-making behaviours.

\section{Methodology}

\subsection{Sampling Technique for the Current Study}

It has been reported that $84 \%$ of the South Korean population are active social media users; this is the highest number of monthly active social media users in the Asia Pacific region [84]. For this study, semi-structured, in-depth interviews were employed. The interview questions for this study were developed through the several processes and contents and themes that the researchers acquired. That is, after conducting the preliminary and pilot studies, the researcher of this current study had a list of themes and prepared questions to be covered. All initials themes and questions were adopted and developed from previous related studies (e.g., [36,63,85-88]). Details of interview question design for the study is provided in Table 1. It is natural for the content of the interviews to vary from interview to interview; some questions can be skipped in accordance with the researchers' intentions. Based on individuals' in-depth interviews, the interview guide was developed and revised to be used in the main part of the interviews. In addition to this, additional questions that the researcher would like to ask were flexibly added to the main interview in order to help explore the research questions and objectives. Moreover, this study aims to adjust the research strategy and data collection processes and analysis as recommended by Creswell [89]. The pilot study was carried out before conducting the main study. The initial respondent, who used to frequently visit cafés and restaurants and seemed to enjoy providing information about what she had experienced on social media pages (e.g., Instagram, Facebook and blogs), was selected and contacted by DM (direct message), which is one of the functions provided by Instagram.

Table 1. Interview question design for the current study.

\begin{tabular}{|c|c|c|}
\hline Research Objectives & Initial Themes & Interview Questions \\
\hline $\begin{array}{l}\text { 1. To explore the key factors related to } \\
\text { adopting social media on smartphones for } \\
\text { interviewees' decision-making process about } \\
\text { selecting a restaurant } \\
\text { (Key references: }[36,63,85-88] \text { ) }\end{array}$ & $\begin{array}{l}\text { 1. The understanding of why consumers } \\
\text { utilise social media on smartphones for their } \\
\text { restaurant decision-making process } \\
\text { 1.1 What features of smartphones attract } \\
\text { consumers to use them for restaurant } \\
\text { decision-making processes } \\
\text { 1.2 What features of social media attract } \\
\text { consumers to utilise them for their } \\
\text { restaurant decision-making process }\end{array}$ & $\begin{array}{l}\text { 1.1 Can you explain why you utilised a } \\
\text { smartphone when you selected a restaurant? } \\
\text { 1.2. Can you explain what features of the } \\
\text { smartphone made you utilise it for the restaurant } \\
\text { decision-making process? (e.g., mobility, } \\
\text { internet connectivity) } \\
\text { 1.3 Can you explain why you utilised social media } \\
\text { when you selected a restaurant for dining? } \\
\text { 1.4 Can you explain what features of social media } \\
\text { on the smartphone made you utilise it for the } \\
\text { restaurant decision-making process? }\end{array}$ \\
\hline
\end{tabular}


Table 1. Cont.

Interview Questions

2.1 What kind of social media did you use for the restaurant decision-making process the last time? Did you utilise different social media in accordance with the stage of the decision-making process?

2.2 Could you explain your experience of utilising social media on a smartphone for the restaurant decision-making process?

2.2.1 Before visiting a restaurant, how do you utilise social media on a smartphone for restaurant selection? Could you describe your experience in detail?

2. To investigate how respondents utilise social media on smartphones for the restaurant decision-making process in accordance with the different consumption stages (i.e., pre-, during, and post-visitation of a restaurant)

(Key references: $[46,56,87,88]$ )
2. The understanding of what kinds of activities using social media on smartphones are performed in accordance with the different stages of the decision-making process 2.1 Before visiting a restaurant, which activities are performed by interviewees 2.2 During visiting a restaurant, which activities are performed by interviewees

2.3 After visiting a restaurant, which activities are performed by interviewees
For example, please explain your decision-making process very specifically. While going to a restaurant, have you ever changed your mind? Or do you always go to the restaurant that you intended to visit?

2.2.2 During your visit to a restaurant, do you utilise social media? If you do, how do you utilise social media on a smartphone? And why do you use social media for doing that activity?

If not, could you explain why you did not use social media on a smartphone after selecting a restaurant?

2.2.3 After visiting a restaurant, how do you utilise social media on a smartphone? And why do you use social media for doing that activity?

If not, could you explain why you did not use social media on a smartphone after selecting a restaurant? Was there any different media or tool that you utilised? Can you explain what kind of activities you did?

3.1 What do you think about using social media on a smartphone for the whole process of selecting a restaurant?

3.2 Do you think that the use of social media on a smartphone influences the process of selecting a restaurant?

3.2.1 If so, could you describe how your restaurant decision-making process has been changed (affected) by utilising social media on a smartphone?

3.2.2 Could you explain how the use of social media on a smartphone will affect your next restaurant decision-making process?

3.2.3 Could you explain how your experience of using social media for selecting a restaurant will affect other people who make a decision about a restaurant?
Achieving deep insights into utilising social media on smartphones for the restaurant selection process

3.3 Are you willing to utilise social media to decide on a restaurant in the near future?

3.3.1 If so, why do you intend to utilise social media again for your next restaurant selection? 3.3.2 Among a variety of characteristics of social media on a smartphone, what do you consider to be the most useful feature?

3.3.3 If not, why you are not going to utilise social media on a smartphone to decide a restaurant for your next visit?

3.3.4 Was there a specific feature or experience that made you not intend to use social media for restaurant selection?

4. Demographic information

5. Information about the restaurant an interviewee visited
4. To understand respondents' background issues with regards to the research

5. To connect restaurant types the respondents visited and the usefulness of social media
Such as gender, age, education, occupation and marital status

Restaurant type (fine dining, casual, quick service), price per person, restaurant name, visited date, location restaurant visit pattern, preferred restaurants 
A snowball sampling technique was adopted to recruit respondents who had experienced restaurant decision making using social media on smartphones. The sampling criteria of selecting participants was limited to people who had utilised social media platforms on smartphones for restaurant selection at least twice in the past three months. In addition, the interviewees were limited to Koreans who use smartphones, as smartphone user penetration rate in Korea is $95 \%$, ranking the country first in the world in 2019 [91]. Based on this, Koreans were regarded as relevant participants for the current study. There was no limitation in terms of respondents' ages. According to Saunders et al. (2010), snowball sampling is employed when researchers have difficulty in identifying suitable members of the required population [92], as this technique relies on referrals from initial subjects to generate additional subjects [93]. After conducting the pilot study on 15-20 March 2015 for the current research, it was identified that recruiting interviewees who utilised social media for their restaurant dining experiences at all stages (pre, during and post stages) is more difficult than the author of this study expected. While Korean people are reported as one of the nationalities that utilise smartphones frequently, fewer social media users utilise smartphones during every stage of the restaurant experience. In other words, the current study needed respondents who actively utilise social media on their smartphones not only for the pre-visiting stage but also during the visit and after visiting, if possible. Thus, respondents who utilised social media at every stage of the restaurant decision-making process were needed for this study. Based on this, snowball sampling was chosen and adopted. Once participants are interviewed, they are asked if they know any other people who have experienced similar decision-making processes. In particular, people who utilise social media actively are likely to know others who are familiar with the use of social media, as there is a strong possibility that they are in the same group. The sampling criteria of selecting participants was limited to a person who had actively used social media for their restaurant decision making. Therefore, the participants were limited to people who had utilised social media platforms on smartphones for restaurant selection at least twice in the past three months; this study requires descriptive and in-depth explanations regarding consumers' decision-making processes, and the author believed that this criterion encouraged informants to recall their own experiences about selecting a restaurant using social media. When performing the preliminary study, the respondents who had at least one experience of using social media on smartphones for their restaurant selection within the past month were selected as relevant respondents; however, the researcher found that many respondents had not uploaded or shared their dining experiences on social media pages, as had been expected from the preliminary study. Thus, the author changed the criteria to overcome the limitation of study sampling by increasing the time period of utilising social media for restaurant selection from the past one month to the past three months. It was possible that the respondents who were referred by other respondents could provide more relevant data that might satisfy the research objectives of this study. Therefore, initial interviewees were identified from among 550 followers of the researcher's Instagram account at the time of data collection based on what they posted on their Instagram pages (e.g., uploading photos of restaurants and cafés). The main interviews took place in South Korea, and the initial interviewees were contacted by text messages. The initial interviewees were selected from among the researcher's Instagram followers who were interested in visiting cafés and restaurants and also enjoyed uploading accounts of their experiences to social media pages. Afterwards, the agreement to cooperate in the research was followed up by phone calls and text messages to establish dates and times. The location of the interviews varied from respondent to respondent. Cafés, offices and restaurants were chosen for the interview locations because of their convenience. All interviews were conducted on a face-to-face basis and were in-depth. Once respondents' interviews were conducted, their referrals played an important role for this study, as the researcher needed to recruit participants who could describe their detailed experiences, including during and after visiting a restaurant, which is regarded as an information-rich case. As a result, a total of 30 interviews were conducted, at which point data saturation 
was considered to be achieved. Each interview was recorded and transcribed for analysis. The study's sample consisted of 21 females and 9 males, aged 25-44 years old. Thematic analysis was adopted for analysing this study [94]. During the coding and searching for themes stages, the researcher moved backwards and forwards repeatedly so as to confirm that the themes generated were correct.

\subsection{Interview Question Design for the Current Study}

The purposes of the interviews were as follows:

- To examine the key factors related to adopting social media on smartphones for interviewees' decision-making process for selecting a restaurant.

- To investigate in depth how respondents utilise social media on smartphones for their restaurant decision-making process in accordance with the different consumption stages (i.e., pre-, during, and post-visitation of a restaurant).

- To evaluate the usefulness of interviewees' social media use on smartphones for their restaurant selection.

- To obtain deep insight into respondents' experiences regarding the restaurant decisionmaking process in their own vivid words.

For an example of transcribed interviews, see Appendix A.

\section{Findings and Discussion}

Thematic analysis of the interview data revealed that the factors influencing consumers' adoption of social media for restaurant decision making are consistent with the U\&G theory. That is, consumers intend to adopt social media for their dining-out decisionmaking process when the three dimensions of gratifications are satisfied. Accordingly, consumers' social media adoption on smartphones is made based on the condition in which they are satisfied with process gratification concerning the information via social media on a smartphone and focusing on the actual use of social media itself. In addition, consumers' gratification regarding the content provided by the medium (i.e., social media in this study) needs to be satisfied for adopting the selected medium.

\subsection{Research Question 1}

"What are the key factors related to adopting social media and the usefulness of social media on smartphones for restaurant selection?"

The current study decided to adopt the uses and gratification theory [63] in order to explain why consumers adopt social media for decision-making processes, as it is regarded that the U\&G theory could be suitable for explaining consumers' social media adoption for their restaurant decision-making process based on the following reasons. First, recent restaurant consumers are regarded as more powerful and goal-directed about their decisionmaking behaviours, especially in the online environment $[64,65]$; thus, this study requires a theory satisfying both decision-makers' social and psychological purposes for examining the key factors related to consumers' social media adoption. Second, consumers' restaurant decisions are not just associated with consuming food but with consumers' total restaurant experience across the three stages of visiting a restaurant. Therefore, the U\&G theory, providing the three dimensions of gratification - process gratification, content gratification and social gratification-is regarded as appropriate for the current study. In this study, it is regarded that process gratification refers to users' satisfaction with the experience of the actual use of the medium itself, and content gratification refers to users' satisfaction with the ability of a medium to convey messages [82]. In addition, social gratification refers to the ability to communicate with other users by utilising the medium and is related to the fulfillment of social expectation [63]. Moreover, this study regarded that the uses and gratification theory was developed based on the notion that consumers intentionally select certain media to fulfill their needs, which can justify the adoption of the theory for this study, as current restaurant consumers are expected to choose and utilise a type of media for their decision-making process in accordance with their purposes and motivations. 
Based on the theoretical notions above, it was identified through this study that consumers intend to adopt social media for their dining-out decision-making process when the three dimensions of gratification were satisfied. Accordingly, consumers' social media adoption on smartphones is made based on the condition in which they are satisfied with process gratification concerning the information via social media on a smartphone and focusing on the actual use of social media itself. In addition, consumers' gratification regarding the content provided by the medium (i.e., social media in this study) needs to be satisfied for adopting the selected medium. More specifically, content gratification is derived from the utilisation of messages that are more related to intrinsic value, compared to process gratification, which focuses more on extrinsic value. As a result, it can be regarded that the research question regarding key factors to adopt social media on smartphones was successfully examined and identified, as summarised in Figure 2.

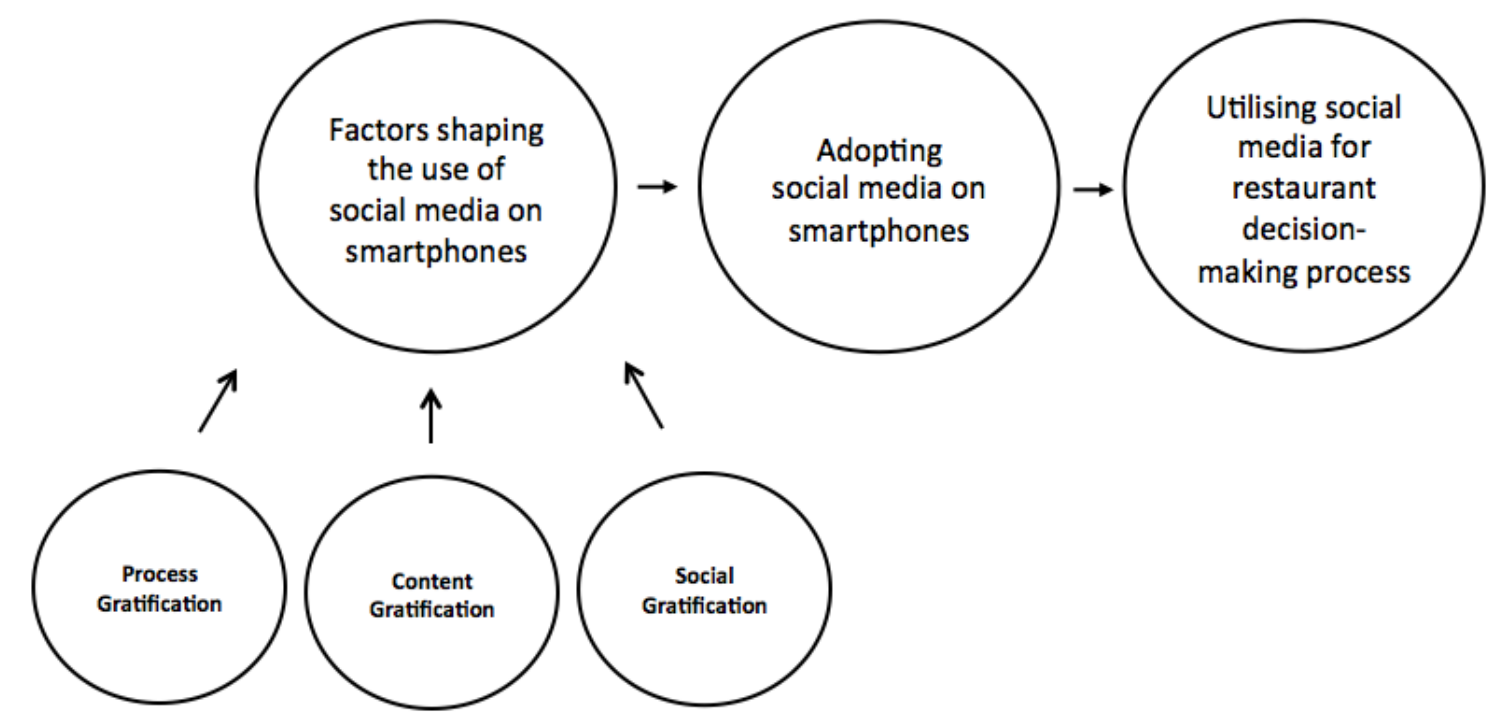

Figure 2. Key factors in adopting social media on smartphones for consumers' restaurant decision-making process. Source: Author's development from research findings.

According to the findings of the current study, it was identified that the adoption of social media on smartphones is positively related with consumers' three dimensions of gratification (process, content and social gratification). Above all, consumers' social media adoption could not be performed without the environment where individuals are ready to utilise technology-based tools. Therefore, it was found that process usefulness was mostly associated with its extrinsic factors: that is, convenience, speedy decision making, GPS, portability, ease of use and accessibility. Regarding content usefulness, restaurant consumers expect to obtain appropriate information about choosing a restaurant by adopting social media. According to the findings, it was identified that specific information, popular dish/place and trustworthiness were the factors satisfying consumers' content usefulness. Lastly, it was examined that social usefulness can be satisfied when consumers' expectation regarding social media adoption meets the following factors: trendiness, essential, success and satisfaction. As such, social usefulness is more related to consumers' psychological and motivational expectations of adopting social media. Based on data obtained from the 30 interviewees of this study, six themes related to the performance of the activity using social media emerged: convenience, speedy decision making, GPS, portability, ease of use, accessibility, and time and place. Respondent 24 also emphasised convenience, giving examples of sending a link or sending captured images to others and getting a rapid reaction. She reported that the function of screen capture helped her to conveniently decide on a restaurant, especially when a group was trying to make a decision. 
"It is really convenient to send a link to a friend on messenger through using a smartphone and to recognise a friend's immediate reaction after I send a friend restaurant reviews on blogs. If I used a laptop for communicating and selecting a restaurant with a friend, it would be difficult to send captured images to a friend. Screen capture of what I found from websites is also a convenient feature of smartphones, I think. Therefore, in my case, I utilised a smartphone, as I was able to send immediately links and screen captures of pages to others."

(Respondent 24, female, aged 25-34)

Speed was found to be one of the central areas of usefulness for utilising social media when deciding on a restaurant. One of the phrases that participants frequently used in the interviews was "speedy decision making was possible" based on the use of social media on smartphones. Respondent 1 mentioned that she would utilise social media the next time, as she considered its aspect of speed to be really helpful when searching for information on a restaurant that she had not previously visited:

"I will definitely utilise social media for my next restaurant selection process, because I am able to get speedy information by using social media, which I regard as a really important aspect for selecting a restaurant. Therefore, I believe that using social media is really helpful for searching for relevant information when visiting a new restaurant that I have never visited before."

(Respondent 1, female, aged 25-34)

Some interviewees mentioned that the GPS function on smartphones helped them to conveniently and easily decide on a restaurant, based on the fact that GPS signals influenced participants to search for a list of restaurants nearby and also to find the exact location of a restaurant. In this regard, Respondent 22 reported that

"Among the many features provided by smartphones, I checked where I was at the moment through GPS signal and easily found a delicious restaurant with good reviews based on the location. In addition, I was able to achieve new and trendy information of restaurants nearby."

(Respondent 22, male, aged 35-44)

Many of the interviewees stated that utilising social media on smartphones is convenient because of portability while they were en route and when they needed to decide on a restaurant. In addition, some respondents utilised social media for their restaurant selection process, as they regarded that social media use based on smartphones did not interrupt their media use activities, regardless of time and place. For instance, Respondent 1 emphasised the smartphone's portability, as she could utilise it in accordance with her needs.

"What I regard about using a smartphone is that ... a smartphone can be utilised regardless of place and time because of its portability, and I believe that my smartphone helps me to search for information I need fast."

(Respondent 1, female, aged 25-34)

Respondent 30 mentioned that she utilised social media when she needed to find other people's reviews, and she easily conducted the search process, as what she needed could be found using just one finger. She emphasised the smartphone's ease of use whenever she needed to find information:

"Through using social media, it is easy to refer to many reviews. Namely, ease of use of social media for searching others' reviews was why I used it. With the use of just one finger, I can see detailed photos and reviews at the same time, and it can become a tool comparing many people's photos and content."

(Respondent 30, female, aged 25-34)

One useful aspect that participants mentioned throughout the interviews was smartphones' accessibility. Interviewees regarded that the use of social media on smartphones 
was more accessible for them compared to other information sources. For example, Respondent 18 stated that she could immediately check and search for information regarding restaurants, as she felt accessibility was good:

"Among many kinds of features provided by smartphones, for me, accessibility and ease of using it were important factors. And I was able to check and see food photos on a social media application immediately. Also, searching for location was very convenient through using a smartphone because it was easily connected to the map application."

(Respondent 18, female, aged 35-44)

Content gratification is derived from the utilisation of messages that are more related to intrinsic value, as compared to process gratification, which focuses more on extrinsic value. According to the results of this study, four themes were identified that could help consumers to be motivated to adopt social media for their restaurant selection process: specific information, popular dish/place, trustworthiness and amount of information. Above all, specific information provided by online review sites was found to be one of the reasons for utilising social media on smartphones to decide on a restaurant. Many recent researchers have found that online reviews from social media influence consumers' purchasing decision-making processes (e.g., $[95,96])$. Participants regarded that they could collect the specific and detailed information they were looking for when deciding on a restaurant. Respondent 4 mentioned that specific and detailed information provided by social media was regarded as an important factor in the usefulness of social media:

“... I utilised Instagram, Facebook, blogs and Kakaostory. At first, I happened to know a restaurant through Instagram and Facebook, then I looked for specific and detailed information through blogs, as I wanted to visit the restaurant I heard about from social media..."

(Respondent 4, female, aged 25-34)

Participants considered social media to be useful for their restaurant decision-making processes because it could help them find popular restaurants and dishes. One of the interviewees described utilising social media for restaurant decisions in order "to find which restaurants are popular and whether a restaurant is in line with my taste and preference" (Respondent 2). The interviewees used social media on smartphones in order to find and then visit popular restaurants and to receive recommendations regarding popular dishes.

"I will utilise social media. I think that the biggest reason why I will adopt social media for my restaurant decision-making process is to conveniently collect information and to grasp the hot trends. Nowadays, it might be important to find which restaurants are popular and whether a restaurant is in line with my taste and preference, because restaurants are very sensitive to trends."

(Respondent 2, Female, aged 25-34)

Several participants expressed their feeling of expectation in utilising social media for their restaurant decision-making process, as they trusted the content compared to other information sources. Respondents' feelings about honest content on social media can be important, as this can be a fundamental factor in using social media. Dickinger mentioned that honesty and sincerity have a high influence on the feeling toward an information source [64]. In terms of trustworthiness, there have been prior studies that have highlighted "trust" between users. Wang and Fesenmaier (2004) indicated that trust is between all the people who contribute or want to contribute some interesting information and is as useful as the knowledge gained by each user or creator of information from other people in the past [46].

Respondent 20 mentioned that she felt she could rely on a blogger's restaurant review and chose a restaurant to celebrate a memorable date, as there was trust between her and the blogger. Compared to other marketing communication regarding restaurant choice, 
she believed that reviews on blogs were honest enough to help her decide on a restaurant for her important occasion:

"At first, I found a restaurant called 'Palais de Gaumont' through a blog that I had been following. I thought that a blogger who posted a review regarding 'Palais de Gaumont' restaurant had the same taste about many things, and I remembered she suggested a restaurant and spoke of it as delicious to other people, which influences me to positively consider it when she uploaded a posting about that restaurant. In my case, performed trust between her and myself influenced my restaurant selection. In addition, the reason to use social media is that there are relatively honest judgments and detailed information such as location and telephone number."

(Respondent 20, female, aged 35-44)

Lastly, in addition to process and content gratification, social gratification was identified to help consumers adopt social media on smartphones for consumers' restaurant selection process. According to Stafford and Stafford (2001), social gratification more concerns users' mutual communication with other people through the medium [97]. Williams et al. (1988) also asserted that social gratification is related to users' interaction with other people via the media that the users chose and adopted for their decision-making process [98].

Participants related their reasons for utilising social media to their preference for visiting a trendy restaurant and/or feeling that they are trendy in choosing a restaurant. Regarding trendiness, one of the researchers who studied consumer behaviours regarding restaurant selection, Mills (2000), identified that the kind of attributes that may cause consumers to visit a restaurant are "innovative" and "trendy", which may imply that innovative and trendy attitudes are relatively strong factors working as a booster to visit a restaurant, even though there could be many different factors affecting consumers' motivation [99]. Based on this finding, the respondents considered being trendy as a good thing when deciding on a restaurant, and they mentioned that the use of social media for visiting a trendy restaurant is helpful. According to Sigala's study (2012), consumers tend to utilise social media to identify new market trends, as social media is regarded as a helpful source for them to find trends [73]. Thus, the respondents of this study utilised social media to find out about popular and trendy restaurants and felt that social media was useful.

One of the participants in the current research, Respondent 14, reported that she was the kind of person who tended to visit popular restaurants, and the postings regarding new and trendy restaurants on social media pages influenced her to select one:

"Yes, I will definitely use social media for the next time. I think I am a kind of person who would like to visit popular and trendy restaurants now because I am easily influenced by postings of new trendy restaurants on social media. I would like to experience and visit those places by myself and want to share my story with others."

(Respondent 14, female, aged 25-34)

Some participants regarded the usefulness of social media on smartphones for their restaurant decision-making processes as essential. According to several respondents in this study, it is natural that they always utilise social media on smartphones to search for information regarding a restaurant, as they would like to choose a restaurant serving delicious dishes. One of the respondents mentioned that there was no option but the utilisation of social media to access knowledge about a restaurant in an unfamiliar place, as the usage of social media through a smartphone could help him to collect relevant information based on his location.

"I think that using social media for deciding on a restaurant is not optional but essential! If I visit an unfamiliar location, I have no choice but to utilise social media for collecting information about delicious restaurants. Otherwise, the information I have about restaurants would be only in my area."

(Respondent 7, male, aged 25-34) 
Another useful aspect mentioned by participants for their social gratification when utilising social media on smartphones was identified as "success". Several interviewees reported that the reason why they utilised social media for their restaurant decision-making processes was to avoid being unsuccessful in choosing a restaurant. Namely, they were desirous of being successful in choosing a restaurant, and this can be seen from what they expressed in the interviews. For example, Respondent 9 mentioned that she tended to utilise social media to decide on a restaurant providing good and delicious food. This tendency to use social media on smartphones for choosing a restaurant was based on her repeated experiences of selecting bad restaurants.

"If I decide on a restaurant without using social media, I tend to choose a restaurant that I just discover by chance, which often brings a high possibility of failure. For example, taste of food is not so good or atmosphere is bad.... However, I think that the probability of successfully visiting a restaurant is more than $80 \%$ based on reviews through utilising social media, which is a relatively high probability."

(Respondent 9, female, aged 25-34)

Another motivational factor for using social media to decide on a restaurant was "satisfaction". Consumer satisfaction can be regarded as one of the most frequently researched subjects for those studying consumer behaviours. According to previous studies on consumers' purchasing decision-making processes, consumers tend to make their purchasing decisions based on what they hear and see through opinions of other people's experience [100]. There are many researchers who have studied the relationship between the use of social media reviews and customer satisfaction, though there is little study regarding the relationship between the utilisation of social media and consumers' restaurant selection. For example, Ramanathan et al. (2017) examined the role of social media in marketing to enhance customer satisfaction and identified that users' reviews on social media positively affect customer satisfaction [74].

Some interviewees in this study reported that the feeling of satisfaction regarding restaurant choice based on using social media was important for them. For example, Respondent 17 said that she tends to utilise social media when deciding on a restaurant, as she had a bad experience of visiting a restaurant without enough prior information. More specifically, her restaurant choice when travelling to Japan was unsatisfying because of her lack of prior information, which affected her use of social media to choose a restaurant. In other words, she would like to be satisfied with her restaurant choice, and the use of social media on a smartphone could help her to be satisfied.

"I think that there is a big difference between conditions where I have enough information and I do not have enough information when visiting a restaurant. For example, not long ago I travelled to Japan without enough information, because I was too busy to properly search and I was not able to speak Japanese, which influenced my satisfaction with the restaurant visit. In other words, whenever visiting a restaurant it was risky and I felt less satisfied. Through these experiences, I was determined to search information and choose a restaurant in advance for next time."

(Respondent 17, female, aged 25-34)

Accordingly, consumers' adoption of social media on smartphones does not just mean that it necessarily fulfills consumers' information searches regarding restaurant selection, but it could explain consumers' complex decision-making behaviours. Although current consumers' adoption of social media for their decision-making process has been regarded as an essential procedure, we should be aware that adopting social media could not be done without satisfying consumers' different dimensions of usefulness, which is investigated by this research. Thus, the scope of explaining consumers' social media adoption can be expanded according to the results of this study. Figure 3 summarises the usefulness of restaurant consumers' social media use. 

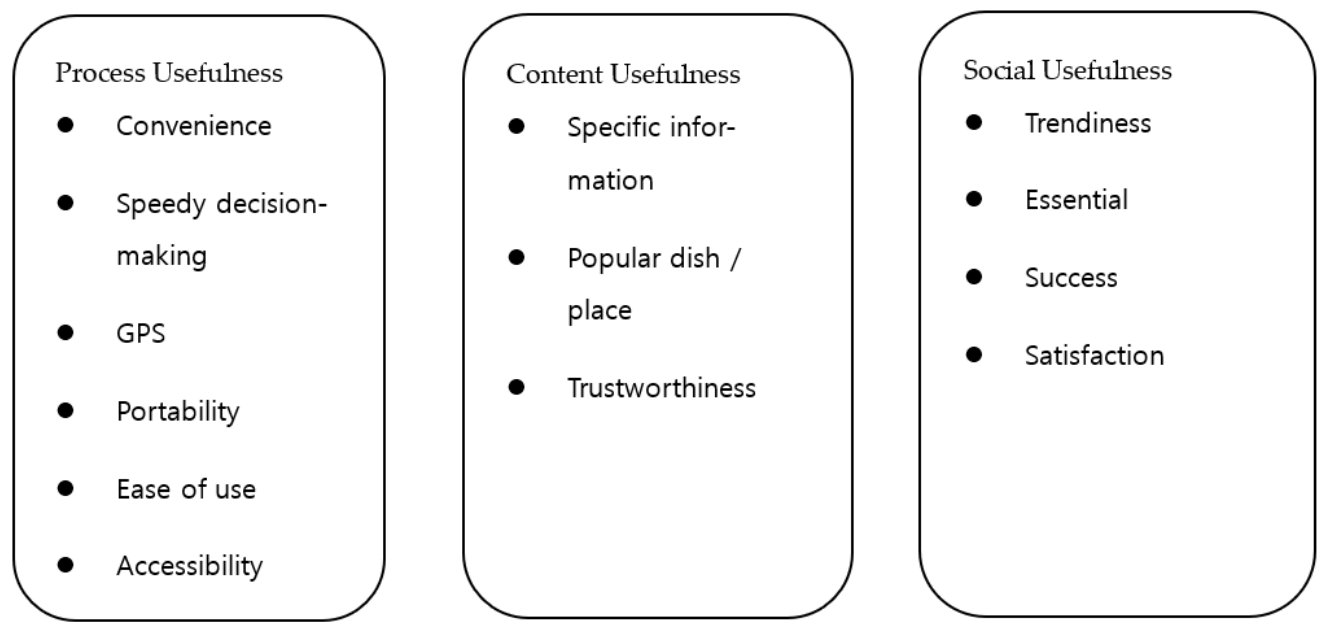

Figure 3. The usefulness of social media use for restaurant decision-making processes. Source: developed from the findings of this study.

\subsection{Research Question 2}

"What is the deep insight into experiences regarding restaurant decision-making processes across all consumption stages?"

\subsubsection{Before Visiting a Restaurant}

This section focuses on what kind of actions respondents performed before they visited a restaurant through using social media. As a result of thematic analysis, three themes of consumer activities emerged: searching for information, minimising risk and group decision making (see Table 2).

Table 2. Thematic coding of data for the use of social media on smartphones before visiting a restaurant.

\begin{tabular}{|c|c|c|}
\hline Activities & Detailed Activities & Sample Quotes \\
\hline \multirow{6}{*}{$\begin{array}{l}\text { Searching for information } \\
\text { (Xiang and Gretzel, 2010, support the } \\
\text { findings of searching for information } \\
\text { before visiting a restaurant [48]) }\end{array}$} & Deciding on a dish & $\begin{array}{l}\text { "I already decided on a menu to some degree before visiting a } \\
\text { restaurant, which caused me not to utilise social media again } \\
\text { while I was visiting a restaurant" (Respondent 10) }\end{array}$ \\
\hline & Deciding on a restaurant & $\begin{array}{c}\text { "Among many reviews, I especially took a closer look at } \\
\text { postings including description of taste in detail and } \\
\text { documenting a kind of food. In the last process, I finally } \\
\text { decided on a restaurant through narrowly observing photos } \\
\text { uploaded by bloggers" (Respondent 12) }\end{array}$ \\
\hline & Looking at photos/images & $\begin{array}{l}\text { "Looking for photos on Yelp pages, I checked on menus by } \\
\text { looking over photos uploaded by bloggers, I can read detailed } \\
\text { photos" (Respondent 10) }\end{array}$ \\
\hline & Making lists of restaurants & $\begin{array}{c}\text { "Narrowing down restaurant lists into three or four, there is a } \\
\text { list providing limited restaurants from Naver blogs" } \\
\text { (Respondent 15) }\end{array}$ \\
\hline & $\begin{array}{l}\text { Checking whether many people have } \\
\text { visited the restaurant or not }\end{array}$ & $\begin{array}{l}\text { "When I was examining reviews provided by previous visitors } \\
\text { on blogs, I focused on checking whether many people had } \\
\text { already visited or not. Through the process of examining } \\
\text { reviews, I discovered there was a popular burger chosen by } \\
\text { many people, which influenced me to decide on the menu } \\
\text { before visiting a restaurant" (Respondent 11) }\end{array}$ \\
\hline & Checking on description of taste & $\begin{array}{l}\text { "In the case of Instagram, there are generally photos with short } \\
\text { descriptions rather than reviews or detailed explanations about } \\
\text { a place, which influenced me to utilise blogs at that time. Then, } \\
\text { I visited Facebook pages of Alex, the coffee, and I read what } \\
\text { people thought. It is difficult to check others' thoughts from } \\
\text { Instagram" (Respondent 23) }\end{array}$ \\
\hline
\end{tabular}


Table 2. Cont.

\begin{tabular}{|c|c|c|}
\hline Activities & Detailed Activities & Sample Quotes \\
\hline $\begin{array}{l}\text { Minimising risk } \\
\text { (Quintal et al., 2010, support the } \\
\text { finding of having indirect } \\
\text { experiences [101]) }\end{array}$ & Having indirect experiences & $\begin{array}{l}\text { "In my case, I used social media for restaurant selection as it } \\
\text { helped me to have indirect experiences. Through the reviews } \\
\text { written by previous visitors, I was able to predict the taste of } \\
\text { foods, the price and atmosphere as well. For me, these features } \\
\text { of social media were quite useful" (Respondent 7) }\end{array}$ \\
\hline \multirow{2}{*}{$\begin{array}{c}\text { Group decision making } \\
\text { (Power and Phillips-Wren, 2011, } \\
\text { support the findings of group } \\
\text { decision making before visiting a } \\
\text { restaurant [102]) }\end{array}$} & Sending information to friends & $\begin{array}{l}\text { "While deciding on a restaurant where all close friends can } \\
\text { gather together after a long time and having a good } \\
\text { atmosphere, Bover Lounge immediately came to mind because } \\
\text { I have heard about it many times through Instagram. I saw } \\
\text { photos of the menu and atmosphere through using the function } \\
\text { of hashtag on Instagram, and I utilised Naver blogs to look for } \\
\text { price, opening hours and break times as well. After searching } \\
\text { information through blogs, I shared the links of blog pages and } \\
\text { photos of food captured by myself with friends through a } \\
\text { Kakaotalk messenger. As a result, my friends and I decided to } \\
\text { visit Bover Lounge, as we all felt that other consumers' reviews } \\
\text { regarding stylish interior design and new and delicious food } \\
\text { were credible" (Respondent 2) }\end{array}$ \\
\hline & Checking suitability & $\begin{array}{l}\text { "At first, I found a place called Bober Lounge from the feed on } \\
\text { Instagram, and when I had a lunch appointment with friends, } \\
\text { my friends and I decided to visit Bober Lounge as a place to } \\
\text { meet. After a promised place was decided, I checked photos } \\
\text { provided by users and examined specifically the menu and } \\
\text { food through using the function of hashtags. Even before } \\
\text { visiting a restaurant, I wanted to examine which menu was } \\
\text { served at a restaurant, and I utilised blogs through typing in } \\
\text { 'Bober Lounge' in the search engine. Through these processes, I } \\
\text { found out which menu was popular and roughly decided what } \\
\text { to order" (Respondent 21) }\end{array}$ \\
\hline
\end{tabular}

Activities using social media conducted by the respondents were mostly related to deciding the most appropriate restaurant for themselves or the group among many available options on social media pages. More specifically, consumers' utilisation of social media on smartphones was associated with searching for information, minimising risk and group restaurant decision-making processes. First, consumers' social media utilisation was related to searching for information; specific activities, such as deciding on a dish, deciding on a restaurant, looking at photos, making lists of possible restaurants, checking whether many people had visited the restaurant and other people's description of taste were identified. Second, consumers' activities to reduce risk emerged as another theme before visiting a restaurant, which supported the findings of Quintal et al. (2010) that consumers' information search process predominantly relates to perception of risk and uncertainty before purchasing [101]. It was found that consumers utilised social media, as they believed that the utilisation of social media was useful to have indirect experiences through checking others' reviews, which is believed to minimise the risk of choosing a restaurant. Third, consumers' social media use on smart phones was related to group decision-making processes. Based on the findings of this study, two kinds of activities were identified: sending information to friends and checking the suitability of a restaurant for members of the group. As such, with the aid of technology development, consumers could easily communicate with their peers about choosing a restaurant, and they could share the content achieved from a social media platform with others before visiting a restaurant.

The utilisation of social media, especially on smartphones, helped respondents to more easily and conveniently make a decision for group dining, as utilising social media on smartphones could provide users with useful information, and its developed functions were appropriate for consumers' group decision-making processes. Conversely, members involved in group decision-making processes using social media can face conformity pressure when they make decisions (Aronson et al., 2007), which can be regarded as a negative impact of social media use for group restaurant decision-making processes [103]. Accordingly, the specific and detailed activities based on the respondents' utilisation of 
social media were determined. According to the findings of the current study, it can be regarded that a large number of activities performed by the respondents (i.e., searching for information and minimising risk) were mostly related to efforts that could help them to choose the most appropriate and favourable restaurant through the processes of using social media. In addition, consumers' restaurant decision-making processes could be performed even with a group with whom they wanted to dine, something that is possible with the aid of smart devices and the useful functions provided by applications. Thus, it may be predicted through this finding that consumers' restaurant decision-making processes are more developed and specifically modified in accordance with their needs through the use of IT devices.

\subsubsection{During Visitation of a Restaurant}

This section focuses on what kind of actions respondents perform when visiting a restaurant when using social media. With smartphones, consumers can now use social media during all stages of their decision-making process [73], which is very different compared to the time when social media and information technologies were not utilised. Namely, there is no limitation of using the developed tools for obtaining what consumers really want. All the names of labels are based on what respondents expressed through their words during the interview procedure. As a result of the analysis, five themes of consumers' activities emerged: doing instant activities, sharing, searching, showing off and did not use (see Table 3).

Now consumers can utilise social media during all stages of their restaurant decisionmaking process, based on the expansion of smartphone adoption and functionality [73]. There are no more obstructions to utilising the developed tools for what consumers want to achieve regarding restaurant selection or dining experiences. According to the findings of the study, four activities conducted by the respondents were identified: doing instant activities, sharing, searching and showing off. Above all, consumers can utilise social media to check in on their own social media account, which is regarded as an instant activity while visiting a restaurant. Regarding checking-in behaviour, Kietzmann et al. (2011) asserted that checking in on social media is regarded as real-time updates on locationspecific information; this action of consumers was mainly related to consumers' emotional motivations rather than connecting functional reasons. Second, sharing information with others emerged as another activity through the findings [107]. Consumers can send photos to others, share opinions with other people, and update photos or their current status on social media pages. It was found through the results of the current research that consumers are now able to create and share what they are experiencing (real-time experiences) with other users online with the aid of the expansion of new media and mobile technologies [104] Third, searching activities were identified as well for the stage of visiting a restaurant. It was found that consumers could search for information at a restaurant and utilise social media again for comparing what other consumers ate at the restaurant. Fourth, the results of this study showed that consumers utilised social media for showing off to others; thus, activities such as tagging people on social media and adding hashtags to photos were done by consumers during visits to a restaurant. Based on the opportunities to share and upload consumers' opinions and experiences online, consumers do not wait until their restaurant visit is finished; they freely show off what they are experiencing from a restaurant. Thus, it can be said that the use of social media and smartphones has increased the chances of sharing consumers' real-time experiences with others, and others' restaurant decision-making processes can also be influenced and affected through these activities conducted by restaurant visitors. 
Table 3. Thematic coding data for the use of social media on smartphones while visiting a restaurant.

\begin{tabular}{ccc}
\hline Activities & Detailed Activities & Sample Quotes \\
\hline Doing instant activities & & "I took a picture with friends with whom I visited a \\
& Checking in on social media & restaurant while visiting the restaurant and checked in on \\
social media" (Respondent 29) \\
$\begin{array}{c}\text { of consumers' instant activities based on } \\
\text { the use of social media [50]) }\end{array}$
\end{tabular}

$\begin{array}{r}\text { Sending photos to others to recommend } \\ \text { a restaurant }\end{array}$
Sharing
Sharing opinions with others via
social media

"When the food that we ordered was served, I took a picture of it and sent it to my wife through smartphone messenger, as I wanted show her and suggest coming together next time" (Respondent 19)

"I left my thoughts about the restaurant I visited on Facebook and shared it with other followers. I did not upload a picture, because there was no photo that suited my taste" (Respondent 13)

(Bødker and Browning, 2012; Litvin et al., 2008, support the findings of consumers' sharing activities through the use of social media $[104,105])$
Uploading photos on my social media

Updating my status to let others know

"In addition to this, I uploaded another food photo through utilising Instagram, as I wanted to show and recommend a restaurant to other followers. When I was visiting a restaurant with friends, it was not easy to upload a photo because I was normally busy chatting with them, but at that time I visited a restaurant with my family, which influenced me to upload a photo" (Respondent 18)

"Since I have a baby, I tend to search information or utilise social media when there is a strong need. In the old days, I used to update my status with the 'check-in' function in social media and usually left reviews regarding my feeling or taste of food, but it has not been easy to do that kind of activity after I had a baby." (Respondent 26)

"During visiting a restaurant, I had to order food, but there was no picture on the menu, which led me to utilise blogs again because I wanted to have a look at real photos of

food on the menu. So, my curiosity about the real

Searching for information before ordering

Searching

(Xiang and Gretzel, 2010, support the findings related to searching activities identified through the current study [48])
Using social media to compare what other people ate

Using social media to get a discount appearance of food can be satisfied because of using social media. Nowadays, it is a kind of habit to search photos before ordering in a restaurant, I think" (Respondent 6)

"I checked through blogs whether there was other food on the menu except cold buckwheat noodles, but there was only cold noodles on the menu when I visited a restaurant. So, I utilised my smartphone to search blogs again to check what other menu was available while I was visiting a restaurant. Then, I asked a server about it and he said that there was no 'Seolung tang' anymore. Therefore, I utilised blogs again to search menu" (Respondent 27)

"Before ordering, I utilised social media because I achieved information such as a discount for the drinks menu, and it was helpful to choose a menu that was good value for money or a delicious menu based on information" (Respondent 22)

"After ordering, I tagged friends who were with me on Instagram because we were all doing Instagram. And I felt that they wanted me to tag them on my Instagram. Frankly I think why I was tagging people on Instagram is kind of showing off or habit" (Respondent 21)

Showing off

Tagging people on social media

(Jacobsen and Munar, 2012, support the findings of showing off identified through the current study [106])

Adding hashtags to photos

"I uploaded a photo on Instagram with the hashtag of the restaurant name after dining was finished, because I wanted to keep a good memory and seem cool to others. I did not provide full information about what I visited on my page, which means that if others want to know about more ..." (Respondent 15)

\section{Did not use}

(supported by the data collected through the current study)
Did not use social media

"I already decide the menu to some degree before visiting a restaurant, which allows me not to utilise social media again while I am visiting a restaurant. Rather than using

social media, I look around at the surroundings and examine what other people were eating" (Respondent 10) 


\subsubsection{After Visiting a Restaurant}

This section focuses on what kind of actions respondents performed through using social media after visiting a restaurant. After the process of analysing, four main themes of consumers' activities emerged: sharing, searching, remembering and not sharing (see Table 4). In addition to the main themes of consumer activities, detailed activities performed by the respondents are explained and discussed.

Table 4. Thematic coding data for the use of social media on smartphones after visiting a restaurant.

\begin{tabular}{|c|c|c|}
\hline Activities & Detailed Activities & Sample Quotes \\
\hline \multirow{6}{*}{$\begin{array}{l}\text { (Pudliner, 2007, supports the } \\
\text { findings of sharing activities } \\
\text { through the use of social } \\
\text { media [108]) }\end{array}$} & $\begin{array}{l}\text { Leaving comments about the taste } \\
\text { of food }\end{array}$ & $\begin{array}{l}\text { "Before eating the food, I could not leave a comment regarding the } \\
\text { taste of the food, but I was able to share my feeling and honest } \\
\text { opinion through social media after I visited a restaurant" } \\
\text { (Respondent 14) }\end{array}$ \\
\hline & & $\begin{array}{l}\text { "Because I was satisfied with the restaurant I visited, I shared my } \\
\text { photos with friends and followers on Kakaostory and messenger as } \\
\text { well. With uploading photos, I also left positive comments based on } \\
\text { my personal experience to recommend the restaurant to others" } \\
\text { (Respondent 6) }\end{array}$ \\
\hline & Leaving a positive comment & $\begin{array}{l}\text { "After visiting a restaurant, I usually utilise social media to share } \\
\text { my experiences and opinions regarding the restaurant I visited. If I } \\
\text { was satisfied with the restaurant, I would recommend the } \\
\text { restaurant to my followers. So, I upload a picture of what I ate and } \\
\text { the atmosphere of the place as well, and l post honestly the reviews } \\
\text { about my experience" (Respondent 5) }\end{array}$ \\
\hline & Posting reviews on blogs & $\begin{array}{l}\text { "Till now, I did not utilise social media after visiting a restaurant, } \\
\text { but I will upload my experience about 'Oh!Tongyoung' restaurant } \\
\text { through using my blog page soon because I usually have a pattern } \\
\text { of uploading reviews and photos after several restaurant } \\
\text { experiences I have. The reason why I would like to share my } \\
\text { experiences with other people is that I also discover a new } \\
\text { restaurant through utilising social media, and satisfaction about } \\
\text { restaurants is relatively high" (Respondent 18) }\end{array}$ \\
\hline & Sharing negative experiences & $\begin{array}{l}\text { "If I was unsatisfied with the restaurant, I would also utilise social } \\
\text { media to let other people know how the restaurant was not good } \\
\text { enough. A main job of utilising social media is, I believe, to share } \\
\text { accurate and honest information with others" (Respondent 5) }\end{array}$ \\
\hline & $\begin{array}{l}\text { Adding hashtags to uploaded } \\
\text { photos }\end{array}$ & $\begin{array}{c}\text { "After visiting a restaurant, I added some hashtags to uploaded } \\
\text { postings in order to provide the fact that the food I had was } \\
\text { delicious..." (Respondent 14) }\end{array}$ \\
\hline $\begin{array}{l}\text { (Kang and Namkung, 2015, support } \\
\text { the findings of searching related } \\
\text { activities through the use of social } \\
\text { media [109]) }\end{array}$ & $\begin{array}{l}\text { Utilising social media to check } \\
\text { others' thoughts }\end{array}$ & $\begin{array}{l}\text { "After visiting a restaurant, I searched again about the restaurant I } \\
\text { visited, as I was wondering why other people felt the pizza was } \\
\text { delicious and their thoughts and feelings. But I did not share or } \\
\text { upload my experiences with others through social media" } \\
\text { (Respondent 30) }\end{array}$ \\
\hline $\begin{array}{l}\text { Remembering } \\
\text { (Supported by the current study) }\end{array}$ & $\begin{array}{l}\text { Utilising social media to remember } \\
\text { a place }\end{array}$ & $\begin{array}{l}\text { "After I visited a restaurant, I also utilised Kakaoplace. There is a } \\
\text { function on Kakaoplace that users can bookmark places where they } \\
\text { visited, which lets other users know the place as well through } \\
\text { utilising Kakaoplace. It also allows me to visit the same restaurant } \\
\text { more easily" (Respondent 7) }\end{array}$ \\
\hline $\begin{array}{l}\text { Not sharing } \\
\text { (Supported by the current study) }\end{array}$ & Not sharing experiences & $\begin{array}{l}\text { "After visiting a restaurant, I normally utilise Kakaotalk to } \\
\text { recommend the restaurant I visited by sharing pictures of the food } \\
\text { and restaurant and sharing my opinion about the restaurant. } \\
\text { However, I seldom leave reviews on social media such as } \\
\text { Instagram, Facebook or Kakaostory, as I usually utilise social media } \\
\text { mainly for hearing news from other friends" (Respondent 4) }\end{array}$ \\
\hline Not utilising social media & Not sharing experiences & $\begin{array}{l}\text { "After having a meal, I kept thinking about the taste of the food, } \\
\text { but I did not upload it. I admit that I am not kind of a person to } \\
\text { share what I experience with others even if really helpful for other } \\
\text { people's specific information searching. I am tied up at that stage } \\
\text { that I just collect information from others" (Respondent 30) }\end{array}$ \\
\hline
\end{tabular}


The utilisation of social media after visiting a restaurant is associated with sharing, searching and remembering. Although sharing and searching activities were identified at the stage during visitation of a restaurant, different objectives and conditions regarding these activities were investigated. While restaurant consumers' searching activities at the stages before and during visitation of a restaurant were mainly connected with choosing a restaurant and/or a dish, consumers' searching activities were changed to checking other consumers' opinions about restaurant service after visiting a restaurant. In addition, consumers' sharing activities showed different purposes compared to during visitation of a restaurant. Namely, consumers' sharing activities were changed to be more accurate and elaborate as their restaurant visit was finished. In addition, activities associated with remembering were identified in consumers' social media utilisation. Consumers utilised their social media to remember a restaurant they had visited after the restaurant visit was finished. Therefore, it can be said that consumers' restaurant selection processes do not finish right after they visit a restaurant. However, consumers still have a chance to search for other people's opinions or communicate with others using social media, which may affect other potential consumers' decision-making processes. Accordingly, all the stages of the restaurant selection process are organically connected and influence one another.

Moreover, there have been meaningful insights and implications regarding consumers' experiences of their restaurant decision-making process. Above all, it is identified that consumers' social media utilisation on smartphones does not stop after deciding on a restaurant but continues to the moments during consuming restaurant experiences. This is clearly different from the previous consumer decision-making models [110] in the hospitality and tourism industry, as most of the previous decision-making models did not cover the stage during which consumers are consuming experiences regarding the purchase. Therefore, it can be regarded that the findings of this study provide deep insight into restaurant consumers' total experiences. Second, according to the findings of this study, consumers' utilisation of social media on smartphones at every stage is organically connected, with each stage influencing the others. Furthermore, other potential consumers' restaurant choice processes could also be affected, as there is no limitation of time and place to utilise social media, and consumers are exposed to the content provided by other users. Third, current consumers' social media utilisation regarding restaurant choice can be more elaborated and developed with accumulated experiences of the restaurant selection process. Furthermore, consumers' social media usage could be more accurate according to their motivation and purposes regarding restaurant choice.

\section{Conclusions}

The framework of the current study can be viewed as a theoretical foundation for understanding how the restaurant decision-making process is performed and the relationship between the use of social media and its impact on dining choice behaviours. Therefore, the findings of this study will contribute to broadening the literature on consumers' restaurant decision-making process and their related behaviours while utilising social media.

\subsection{Theoretical Contribution}

The current research attempts to provide a comprehensive picture of the impact of restaurant consumers' social media use as a whole, throughout the restaurant decisionmaking process. The findings show consumers' distinctively different usages of social media in both behavioural and motivational aspects across the different stages of the decision-making process. Social media is utilised during all stages of the restaurant decision-making process (before, during and after visiting a restaurant), which can answer RQ1 and RQ2 of this study:

"What are the key factors related to adopting social media and the usefulness of social media on smartphones for restaurant selection?"

"What is the deep insight into experiences regarding restaurant decision-making processes across all consumption stages?" 
Above all, it has been recognised by many previous researchers that social media plays an important role before visiting a restaurant for individuals searching for travel-related information $[38,111]$. Deciding on a restaurant is a process of consumer decision making. Therefore, the information search is one of the most important steps for individuals to reach their final decision [54,112]. Accordingly, online reviews, descriptions and/or comments provided by actual users could satisfy what consumers want to know, especially before visiting a restaurant. Moreover, it was found that searching for information with regard to restaurant selection using social media creates more results than typing in other keywords, which can imply that consumers' restaurant decision-making needs are based on a lot of information, as restaurant choice has much uncertainty compared to other purchasing decisions. Therefore, consumers' activities of information searching and minimising risk before visiting a restaurant could be regarded as an essential procedure.

During a visit to a restaurant, smartphones can be utilized, regardless of time and place. This affects the restaurant selection process as well, as consumer utilisation of social media through smartphones continues even while they are visiting a restaurant. Regarding this, Tussyadiah (2012) asserted that consumers are now able to share their decisions and instantly receive reactions and acknowledgement through the adoption and utilisation of social media [50]. Chung and Koo (2015) also revealed that individuals are able to share and upload real-time information on social media [113]. Furthermore, the chances of sharing real-time experiences with others have been increased based on the expansion of new media and mobile technologies [104,105,114].

Lastly, at the stage after visiting a restaurant, it was shown that consumers tend to create online reviews through social media pages, which can provide helpful information for potential customers who are considering consuming intangible products, including restaurant visits. According to the study done by Liu and Park (2015), consumer reviews can be especially important in buying experiential goods (e.g., hotels and restaurants), as consumers usually find it difficult to assess the quality of such intangible products before they actually consume them [115]. Therefore, consumers' activities related to leaving comments about the taste of the food they had eaten when their restaurant visit was finished; this information could be valuable for others. To support this idea, Zhang et al. (2010) found that consumer-generated reviews about the quality of food, environment and service of restaurants are positively related with the online popularity of restaurants [116]. Namely, positive online reviews provided by real previous visitors could affect other potential consumers' intentions to visit the same restaurant. In this sense, Kang and Namkung (2015) proved that the utilisation of social media can be influential for potential restaurant consumers and can affect their decision-making process [109]. In addition, there could be consumers who want to leave negative reviews after their restaurant visit. Through expressing their negative feelings based on their restaurant experiences, consumers' need to share accurate information with other consumers is satisfied. In addition, it can be regarded that consumers' ways of using and exploiting social media are also developed and varied according to the wide expansion of mobile technology. According to Harmon-Jones and Harmon-Jones (2012), this kind of activity performed by consumers can be explained by the cognitive dissonance theory [117]. It is identified through cognitive dissonance theory that when a consumer faces an unsatisfactory consumption experience (conflicting with their beliefs), an individual is more likely to present their negative feelings in a variety of ways (e.g., leaving negative online reviews).

Accordingly, now consumers' restaurant decision-making processes do not finish right after they have had a meal, because they could still search for and find others' thoughts regarding the same restaurant after visiting a restaurant. Furthermore, it could be regarded that consumers' social media usage after visiting a restaurant is associated with mutual communication with other followers, and there is a possibility that this kind of activity may influence social media users' next decision-making processes as well. Based on this reasoning, it is suggested by this study that consumers' restaurant decision-making processes need to be understood in that each stage of the decision-making process is not 
independent; all the stages of the restaurant selection process are organically connected and influence one another.

Furthermore, based on the findings of the current study, current consumers' restaurant decision-making processes can be explained and compared through applying Teare's decision process model (1998); this model provides the process of the during-purchase stage, which examines how service consumption delivery is conducted [110]. Different from what Teare's decision model explained, it was found that consumers' restaurant decisionmaking process is not simply influenced by the level of involvement regarding information searching time on decisions; current restaurant selection is more affected by other factors. With regard to consumers' involvement in a restaurant choice, previous studies categorised types of restaurant decisions as high involvement or low involvement [118]. According to this categorisation, consumers may be highly involved in restaurant decision-making when they need to decide on a full-service restaurant, but consumers are not very involved in decision making when deciding on a fast-food restaurant. Although the current study does not look at type of restaurant, it was found that current consumers' involvement in restaurant decision-making processes is not predominantly decided by a restaurant type but is more affected by other factors, such as dining purposes, occasions and motivations.

In addition, according to the previous literature, restaurant decision making is regarded as a more flexible and uncertain task than product purchasing [30]; however, it was found that current consumers' restaurant selection is influenced by what they are exposed to with the use of social media. When consumers were affected by vivid and favourable images about a restaurant uploaded on online review sites, they could decide on a restaurant in a short time. This shows that consumers' restaurant decision-making processes can combine or overlap some stages of the decision-making process rather than following every stage of the decision-making process, as proposed by previous researchers $[15,111]$. Accordingly, based on this reasoning, consumers' dining selection process cannot be understood as a single simple strategy, as there are various information sources that consumers can utilise for their choice process, especially in the current technological environment. Moreover, the flexibility of a restaurant decision maker is acknowledged in this study; thus, consumers' restaurant decision-making processes can still be understood and explained through the previous studies examining the possibility of flexibility in consumers' decision-making behaviours (i.e., adaptive decision making and heuristic decision making).

The findings of the current research could broaden the literature in the restaurant industry by providing information on how group dining decision processes are conducted, especially before visiting a restaurant. It was identified by this study that current consumers' restaurant decision-making processes can be easily performed with members of a group, as there is the aid of smart devices and useful functions provided by applications. Power and Phillips-Wren (2011) revealed that information technologies have continued to provide opportunities to change the decision-making behaviours of individuals, groups and organisations [102]. According to the respondents of this study, their group decisionmaking process could be conducted effectively with the aid of smart devices and effective IT applications. In this context, social media and Web 2.0 technologies can both positively and negatively impact the effectiveness and rationality of decision-making processes. More specifically, compared to the individual restaurant decision-making processes, group decision-making processes can be more complex, as there is a need to satisfy all decision makers and to effectively communicate with all group members, which can be regarded as "peer influence" [87]. According to conformity theory, informational conformity can have an impact on decision making, as the decision maker turns to the members of his or her social network to achieve accurate information $[103,119]$. Normative conformity may also lead to biased decisions, as the decision maker conforms in an attempt to be accepted by the members of one or more social networks based on peers' expectations. Therefore, it can be asserted based on the discussion above that social media on smartphones can be used for consumers' group decision making, but it demands decision makers' sensible 
utilisation, as there is a possibility of negative issues arising among group members (i.e., conformity and peer influence issues).

Based on utilising social media through their smartphones, consumers could easily communicate with their peers to decide on a restaurant where they would like to dine together and share content that each member might regard as important to reach a mutual decision. Therefore, the expansion of developed IT devices can play a central role in consumers' restaurant selection processes. Thus, we find that consumers' restaurant decision-making processes are more developed and specifically modified in accordance with the development of IT devices. Interestingly, it is suggested by this research that the boundary between during consumption and post-consumption is blurred with regard to information search behaviours, which implies that current consumers are now able to freely express their experiences of products/services while simultaneously consuming them. That is, people do not have to wait to indicate their feelings and thoughts until they can access a certain device and remind themselves of previous experiences. Rather, consumers can provide instant and concurrent information during the purchase of products, which improves the reliability of information quality (see Figure 4).

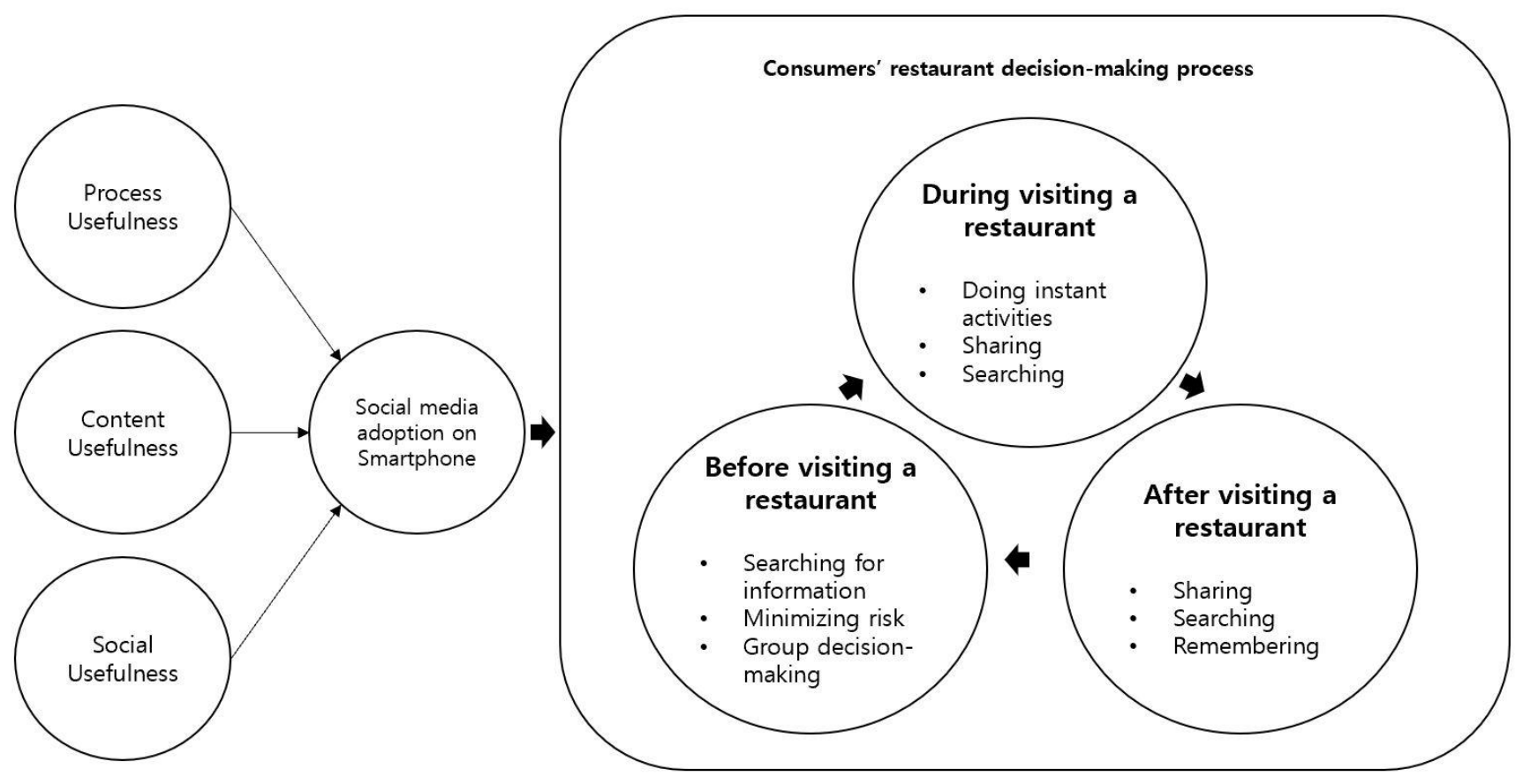

Figure 4. The findings of this study.

\subsection{Practical Contribution}

From the practical contribution perspective, based on the findings of this study, marketers in the tourism and hospitality field can actively and dynamically utilise social media to meet the diverse needs of their consumers relevant to information search and communication during the entire consumption process. Thus, the recognition of different consumption stages could be a critical element to make social media marketing successful in association with technology-based marketing.

More specifically, marketers in the restaurant industry are currently expected to more actively perform marketing strategies based on the aid of GPS, which informs consumers' social media utilisation points. For instance, restaurant practitioners may highlight real consumers' positive reviews regarding restaurants, to be easily exposed when consumers approach an area in which the restaurants are located. In addition, it is advised that restaurant practitioners regularly manage consumers' positive/negative comments about their restaurant experiences. Based on the findings of this study, it was identified that 
restaurant customers would change their mind even after going to a restaurant. Therefore, this study shows that more efforts are needed by practitioners to immediately manage and respond to negative reviews.

In addition, the findings of this study can be beneficial for restaurateurs who plan to develop and employ restaurant apps/social media for attracting more potential consumers, as now they have knowledge of which activities are performed by consumers in accordance with the different stages of restaurant choice. The findings of the current research show that consumers' social media usage does not stop, even while they are eating food at a restaurant; consumers' experiences regarding a restaurant visit can be uploaded and shared with other followers on social media platforms and/or their acquaintances with the aid of technology in the digital era. Therefore, restaurant practitioners need to carry out dining service with care at all points of providing service to consumers. This also suggests that an application/social media on smartphones that users can utilise to identify information in real time would be more useful for potential consumers [120,121].

\subsection{Limitations and Future Study}

While the current research identified interesting findings, there were a few limitations. First, although the purpose of the current research is to achieve deep insights into consumers' social media usage for their restaurant selection and dining experiences from information-rich informants, it should be noted that generalising the findings of this study to all consumers of restaurants could be limited, as this research adopted the qualitative research method, with a limited number of informants and based on a geographically particular location (in South Korea). Second, the age group of the respondents was limited to people in their between $20 \mathrm{~s}$ and $40 \mathrm{~s}$, and this could affect the results of this study. According to the survey conducted by Independent (2017), people who are aged 18-35 tend to spend five whole days a year browsing food images on Instagram, and the respondents of this study show similar tendencies [121,122]. Moreover, this limited age group can be viewed in light of the findings suggested by Bolton et al. (2013) that the millennial generation can be more involved with social media and have a higher motivation to decide travel-related decisions online [123]. Above all, as the current research was limited to consumers in South Korea, it is suggested for future research to consider additional factors to better understand the usage and impact of social media on decision-making behaviours. Second, different types of restaurant can be considered for future studies. Third, if future researchers obtain restaurants' characteristics for research, this would bring different results, which could widen the scope of relevant studies in the restaurant industry. Last, rather than focusing mainly on individuals' restaurant decision-making processes, research regarding group restaurant decision-making processes with the aid of social media and smartphones can provide broad and practical implications and broaden the literature in the restaurant industry.

Author Contributions: J.H., writing of original draft; A.E., review, editing and supervision; J.L.S. review and supervision. All authors have read and agreed to the published version of the manuscript.

Funding: This work was supported by the Ministry of Education of the Republic of Korea and the National Research Foundation of Korea (NRF-2020S1A5B5A17091830).

Institutional Review Board Statement: Not applicable.

Informed Consent Statement: Not applicable.

Data Availability Statement: Not applicable.

Conflicts of Interest: The authors declare no conflict of interest. 


\section{Appendix A}

A sample of a transcribed interview: Transcripts from Interview 26.

The author: Could you tell me about the restaurant you visited and the range of price per person as well?

Respondent: The name of restaurant I visited was 'Seven springs' at Hong Ik university branch. The price per a person was around 15 pounds.

The author: Can you explain why you utilised a smartphone when you made a decision about selecting a restaurant?

Respondent: Above all, my family and I wanted to eat out because it was weekend. While we were deciding restaurant type and menu, there was an opinion of wanting fresh vegetables and salads, which influenced us to choose 'Seven springs'. Although there was a near branch, which is called 'Jamwon', I knew that 'Jamwon' branch did not serve very fresh food based on my prior experience. So, I utilized my smartphone to search other customers' reviews according to different branches, because I wanted to find out which branch provided delicious and fresh food. I found out that there were delicate differences between the branches, for example, in the freshness of prepared vegetables and taste of the menu, even though the same menu was provided. Through these search processes using my smartphone, I found out Hong Ik university branch was better than the others. In my case, I decided first the restaurant where I would visit, but I utilized a smartphone for finding out which branch was better in terms of taste of food and quality of amenities. For example, I looked through reviews provided by consumers to find out whether there was a baby chair.

The author: Could you explain what features of the smartphone made you utilise it for the restaurant decision-making process?

Respondent: With using a smartphone, it is really convenient to search information at any time, but if I use other tools, for example, a laptop, I have to move to turn it on, which takes a longer time. Therefore, I utilized my smartphone, as it was simple to search and find information. Also, transportability and Internet connectivity are good when I am using my smartphone.

The author: Can you explain why you utilised social media when you selected a restaurant to dine? And could you explain what features of social media on the smartphone made you utilise it for the restaurant decision-making process?

Respondent: Frankly speaking, I do not believe what restaurateurs advertise regarding their restaurants. In terms of selecting a restaurant, I think that reviews provided by other people who already visited the restaurants are more trustworthy than advertisements. Through others' reviews, I can have indirect experiences in advance, and referring to others' reviews is really helpful for choosing a restaurant. Personally, I have not uploaded reviews on social media after I visit a restaurant, but there have been many cases that I felt that reviews I looked through regarding a certain restaurant were right. Therefore, now I believe in utilization of social media for restaurant choice.

The author: What kind of social media did you use for the restaurant decision-making process last time? Did you utilise different social media in accordance with the stage of the decision-making process?

Respondent: I utilised mostly blogs at that time and usually ... I utilise Kakaostory as well for restaurant selection.

The author: Before visiting a restaurant, how do you utilise social media on a smartphone for restaurant selection? Could you describe your experience in detail?

Respondent: Naver provides a bookmark application where consumers can leave reviews for finding a restaurant; therefore, I usually refer to those reviews provided by consumers. Those reviews are based on five stars, and reviews can judge restaurants by leaving short comments. In my case, I tend to choose a restaurant based on their comments like 'It was just okay', 'Waiting time was so long' or 'Service level was quite low'. Furthermore, I do not usually choose a restaurant if the atmosphere shown on the photos is not good of if I find that photos on social media are uploaded by people who have a similar 
situation to me, I tend to prefer the reviews provided by them. For example, if people who have a child visited a certain restaurant, I am able to check whether the restaurant is recommended to visit with having a buggy. So, I can check detailed situations by using social media. Once, my husband and I decided on a restaurant and performed a Naver map application in order to type in the address of the restaurant. In that case, we found negative reviews regarding the restaurant where we were heading. Sometimes, we change our decision regarding a restaurant while we are on our way to a certain restaurant. In that case, I can change the destination after searching for new restaurant in the car. I assume that this kind of situation is caused by social media usage on a smartphone. Moreover, as a housewife, I frequently use Kakaostory. Based on what I looked at from Kakaostory, for instance photos, I am able to find a nice place to visit. Then, I search more information from blogs to achieve related information regarding restaurants, and I can decide on the menu.

The author: During a visit to a restaurant, do you utilise social media? If you do, how do you utilise social media on smartphone? And why do you use social media for doing that activity? If you do not utilise social media, could you explain why you do not use social media on a smartphone after selecting a restaurant?

Respondent: While I was visiting a restaurant at that time, I did not utilize social media for that special occasion, as the restaurant I visited was a kind of buffet restaurant, which made me not search more about menu. Since I have a baby, I tend to search information or utilize social media when there is a strong need. In the old days, I used to update my status with the 'check-in' function on social media and usually left reviews regarding my feelings or the taste of the food, but it has not been easy to do that kind of activity after I had a baby. On the contrary, if my child is in a good mood on that day, I tend to take a picture and update social media because I want to boast of beautiful memories with my child. Also, there is a tendency to focus on uploading photos of my child, as my family can visit and see my social media page to see their granddaughter. But at that time, I beautifully arranged dishes before eating them and took a picture. Then, I started eating.

The author: After visiting a restaurant, how do you utilise social media on a smartphone? And why do you use social media for doing that activity? If you do not utilise social media, could you explain why you do not use social media on a smartphone after selecting a restaurant? Was there any different media or tool that you utilised? Can you explain what kind of activities you did?

Respondent: If I visit a restaurant that I am really satisfied with, I usually upload photos taken while I was visiting the restaurant; however, there is the case that I had to refrain from uploading my status on social media, as that kind of activity can be seen as showing off to others who visit my page. In addition to this, my parents might think that I go out too frequently, as they can see my status and photos from my social media. This situation happens more frequently since my parents and I became friends on social media.

The author: What do you think about using social media on a smartphone for the whole process of selecting a restaurant?

Respondent: As advantages of using social media ... I assume that most people have worries about what to eat today ... After using social media, people may visit a restaurant having detailed information, which influences people to have a feeling of relief. Also, they may have more expectation of having a delicious meal because they utilized social media in advance. Therefore, if their meal was satisfactory, they could feel like it was more delicious and might feel great with using social media and searching information. On the contrary, if the restaurant selection was a failure, I would shirk responsibility of choosing an unsatisfactory restaurant, and the level of disappointment can be higher. So, I feel like ... I am diligently trying to searching information from blogs.

The author: Do you think that the use of social media on a smartphone influences the process of selecting a restaurant?

Respondent: I think when I am using social media for restaurant selection, the level of satisfaction can be high, but the level of disappointment can be much higher. So, if I visit a restaurant and I am satisfied with the taste of the food at a restaurant when passing 
though, I would just feel grateful for my choice and I would react like 'it can happen'. However, after I search and gather information regarding a restaurant through social media in advance, if a restaurant is not that satisfactory, I would feel more disappointed.

The author: Are you willing to utilise social media to decide on a restaurant in the near future? If so, why do you intend to utilize social media again for your next restaurant selection?

Respondent: There can be bloggers who find delicious restaurants by themselves and leave reviews based on their real experiences. In the past, I did not save them on blog list or add them as a friend, but now I can say that I have skills for how I act after I find trustworthy bloggers or reviewers on social media; these are developed through repeated searching and selection processes. For example, I have the ability to classify whether this is an advertisement type of review or not. After I visit a restaurant based on a blogger's recommendation, and if I am satisfied with restaurant selection, I tend to add the blogger as a friend on social media for searching information next time. In addition, I can have a look at what the blogger newly uploads and I can even visit a place where I have not thought about before. So, the range of restaurant selection can be wider, as I can have more trust in the content provided by a certain blogger. In the past, when social media and reviews were not like now, there was a popular site called "menupan.com" that I used to visit and gather information from. Now, the trends have changed a lot. But in the past, there was the same need to gain information like now, so review formats and social media tools are more professional as consumers' needs and experiences are detailed and collected. Therefore, I will continuously utilize social media for selecting a restaurant, and when my child is grown and I have more time in the future, I would like to share my experiences through revitalizing my blog, because I also want to be a helpful reviewer for people who need information for their decision. Clearly I have an intention to share reviews and experiences through using social media.

The author: Could you explain how your experience of using social media for selecting a restaurant will affect other people who make a decision about a restaurant?

Respondent: It is really important to have the ability to distinguish which contents are advertisements and which ones are real reviews provided by consumers. In addition, if a blogger updated and shared real and experienced reviews on a blog, it would be helpful to save separately for restaurant decision-making next time.

The author: How many times do you go to restaurants per a month?

Respondent: Four to five times a month.

\section{References}

1. Jeng, J.; Fesenmaier, D.R. Conceptualizing the travel decision-making hierarchy: A review of recent developments. Tour. Anal. 2002, 7, 15-32. [CrossRef]

2. Sirakaya, E.; Woodside, A.G. Building and testing theories of decision making by travellers. Tour. Manag. 2005, 26, 815-832. [CrossRef]

3. Auty, S. Consumer choice and segmentation in the restaurant industry. Serv. Ind. J. 1992, 12, 324-339. [CrossRef]

4. Namkung, Y.; Jang, S. Does food quality really matter in restaurants? Its impact on customer satisfaction and behavioral intentions. J. Hosp. Tour. Res. 2007, 31, 387-409. [CrossRef]

5. Ponnam, A.; Balaji, M.S. Matching visitation-motives and restaurant attributes in casual dining restaurants. Int. J. Hosp. Manag. 2014, 37, 47-57. [CrossRef]

6. Jung, J.M.; Sydnor, S.; Lee, S.K.; Almanza, B. A conflict of choice: How consumers choose where to go for dinner. Int. J. Hosp. Manag. 2015, 45, 88-98. [CrossRef]

7. Filimonau, V.; Krivcova, M. Restaurant menu design and more responsible consumer food choice: An exploratory study of managerial perceptions. J. Clean. Prod. 2017, 143, 516-527. [CrossRef]

8. Restaurant Insights Report. How Diners Choose Restaurants. 2017. Available online: https://restaurantsuccess.touchbistro.com/ touchbistro-blog/how-diners-choose-restaurants-report (accessed on 26 December 2020).

9. Google and Nielson. Life360 Mobile Search Moments Q4. 2013. Available online: https://www.thinkwithgoogle.com/qs/ documents / 657/creating-moments-that-matter_research-studies.pdf (accessed on 2 January 2021).

10. Gretzel, U.; Koo, C. Smart tourism cities: A duality of place where technology supports the convergence of touristic and residential experiences. Asia Pac. J. Tour. Res. 2021, 26, 352-364. [CrossRef] 
11. Sharmin, F.; Sultan, M.T.; Badulescu, D.; Badulescu, A.; Borma, A.; Li, B. Sustainable destination marketing ecosystem through smartphone-based social media: The consumers' acceptance perspective. Sustainability 2021, 13, 2308. [CrossRef]

12. Ozdemir-Guzel, S.; Bas, Y.N. Gen Z Tourists and Smart Devices. In Generation Z Marketing and Management in Tourism and Hospitality; Palgrave Macmillan: Cham, Switzerland, 2021; pp. 141-165.

13. Gregory, S.; Kim, J. Restaurant Choice. J. Foodserv. Bus. Res. 2004, 7, 81-95. [CrossRef]

14. Crotts, J.C. Consumer decision making and prepurchase information search. In Consumer Behavior in Travel and Tourism; Mansfeld, Y., Pizam, A., Eds.; The Haworth Hospitality Press: New York, NY, USA, 1999.

15. Nicosia, F.M. Consumer Decision Process: Marketing and Advertising Implications; Prentice Hall: Englewood Cliffs, NJ, USA, 1966.

16. Howard, J.A.; Sheth, J.N. The Theory of Buyer Behavior; Wiley: New York, NY, USA, 1969; Volume 14.

17. Bettman, J.R. An Information Processing Theory of Consumer Choice; Addison Wesley: Boston, MA, USA, 1979.

18. McKechnie, S. Consumer buying behaviour in financial services: An overview. Int. J. Bank Mark. 1992, 10, 5-39. [CrossRef]

19. Murray, K.B. A test of services marketing theory: Consumer information acquisition activities. J. Mark. 1991, 55, 10-25. [CrossRef]

20. Berné Manero, C.; Ciobanu, A.V.; Pedraja Iglesias, M. The electronic word of mouth as a context variable in the hotel management decision-making process. Cuadernos de Gestión. 2020, 20, 111-136. [CrossRef]

21. Iglesias, M.P.; Guillén, M.J.Y. Searching for information when selecting a restaurant. Food Serv. Technol. 2002, 2, 35-45. [CrossRef]

22. Choudhury, D. Artificial Intelligence in the Hospitality Sector. In Insights, Innovation, and Analytics for Optimal Customer Engagement; IGI Global: Dauphin County, PA, USA, 2021; pp. 257-278.

23. Pedraja, M.; Yagüe, J. What information do customers use when choosing a restaurant? Int. J. Contemp. Hosp. Manag. 2001, 13, 316-318. [CrossRef]

24. Buchtal, K. Growing up. Restaur. Inst. 2006, 116, 67-70.

25. Cha, S.S.; Seo, B.K. The Effect of Food Delivery Application on Customer Loyalty in Restaurant. J. Distrib. Sci. 2020, 18, 5-12.

26. Kim, Y.G.; Eves, A.; Scarles, C. Building a model of local food consumption on trips and holidays: A grounded theory approach. Int. J. Hosp. Manag. 2009, 28, 423-431. [CrossRef]

27. Cha, S.S.; Noh, E.J. A Study on HMR Selection Attributes and Health Values of College Students. J. Ind. Distrib. Bus. 2020, 11, $17-25$.

28. Fu, Y.Y.; Parks, S.C. The relationship between restaurant service quality and consumer loyalty among the elderly. J. Hosp. Tour. Res. 2001, 25, 320-326. [CrossRef]

29. Mozeik, C.K.; Beldona, S.; Cobanoglu, C.; Poorani, A. The adoption of restaurant-based e-service. J. Foodserv. Bus. Res. 2009, 12, 247-265. [CrossRef]

30. Park, S.; Fesenmaier, D.R. Travel Decision Flexibility. Tour. Anal. 2014, 19, 35-49. [CrossRef]

31. Labrecque, J.; Ricard, L. Children's influence on family decision-making: A restaurant study. J. Bus. Res. 2001, 54, 173-176. [CrossRef]

32. Seo, S.H.; Yoon, E.J. Influence of Family Type on Family Dining Decision Maker: Casual Dining Restaurant versus Fast Food Restaurant. J. Hotel. Adm. 2011, 20, 99-115.

33. Chen, Y.S.; Lehto, X.; Behnke, C.; Tang, C.H. Investigating children's role in family dining-out choices: A study of casual dining restaurants in Taiwan. In Proceedings of the 18th Annual Graduate Education and Graduate Student Research Conference in Hospitality and Tourism, Seattle, WA, USA, 3-5 January 2013.

34. Smith, D.; Menon, S.; Sivakumar, K. Online peer and editorial recommendations, trust, and choice in virtual markets. J. Interact. Mark. 2005, 19, 15-37. [CrossRef]

35. Choi, J.; Yoo, D. The Impacts of Self-Construal and Perceived Risk on Technology Readiness. J. Theor. Appl. Electron. Commer. Res. 2021, 16, 1584-1597. [CrossRef]

36. Kaplan, A.M.; Haenlein, M. Users of the world, unite! The challenges and opportunities of Social Media. Bus. Horiz. 2010, 53, 59-68. [CrossRef]

37. Sohail, S.S.; Siddiqui, J.; Ali, R. Feature extraction and analysis of online reviews for the recommendation of books using opinion mining technique. Perspect. Sci. 2016, 8, 754-756. [CrossRef]

38. Bhole, B.; Hanna, B. The effectiveness of online reviews in the presence of self-selection bias. Simul. Model. Pract. Theory 2017, 77, 108-123. [CrossRef]

39. Koyuncu, C.; Lien, D. E-commerce and consumer's purchasing behaviour. Appl. Econ. 2003, 35, 721-726. [CrossRef]

40. Hudson, S.; Gilbert, D. The internet and small hospitality businesses: B\&B marketing in Canada. J. Hosp. Leis. Mark. 2006, 14, 99-116.

41. Lin, Y.L.; Lee, T.J. The impacts of the online reservation system in London city Hotels. J. Hosp. Mark. Manag. 2009, 19, 82-96. [CrossRef]

42. Doolin, B.; Burgess, L.; Cooper, J. Evaluating the use of the Web for tourism marketing: A case study from New Zealand. Tour. Manag. 2002, 23, 557-561. [CrossRef]

43. Taylor, M. Nearly 40 Percent of Dining Experiences Involve a Smartphone. 2019. Available online: https://www.qsrmagazine. com/outside-insights/nearly-40-percent-dining-experiences-involve-smartphone (accessed on 11 September 2020).

44. Leung, D.; Law, R.; van Hoof, H.; Buhalis, D. Social media in tourism and hospitality: A literature review. J. Travel Tour. Mark. 2013, 30, 3-22. [CrossRef] 
45. Dellarocas, C. The digitization of word of mouth: Promise and challenges of online feedback mechanisms. Manag. Sci. 2003, 49, 1407-1424. [CrossRef]

46. Wang, Y.; Fesenmaier, D.R. Modeling participation in an online travel community. J. Travel Res. 2004, 42, 261-270. [CrossRef]

47. Sanchez-Franco, M.J.; Rondan-Cataluña, F.J. Virtual travel communities and customer loyalty: Customer purchase involvement and web site design. Electron. Commer. Res. Appl. 2010, 9, 171-182. [CrossRef]

48. Xiang, Z.; Gretzel, U. Role of social media in online travel information search. Tour. Manag. 2010, 31, 179-188. [CrossRef]

49. Gursoy, D.; Del Chiappa, G.; Zhang, Y. Preferences regarding external information sources: A conjoint analysis of visitors to Sardinia, Italy. J. Travel Tour. Mark. 2017, 34, 806-820. [CrossRef]

50. Tussyadiah, I.P. A concept of location-based social network marketing. J. Travel Tour. Mark. 2012, 29, 205-220. [CrossRef]

51. Kim, E.E.K.; Mattila, A.S.; Baloglu, S. Effects of gender and expertise on consumers' motivation to read online hotel reviews. Cornell Hosp. Q. 2011, 52, 399-406. [CrossRef]

52. Tripadvisor. New Research: 2017 TripAdvisor Restaurant Marketing Study. Available online: https://www.tripadvisor.com/ TripAdvisorInsights /w605?utm_campaign=Chefs\%2BTech\%20Newsletter\&utm_source=hs_email\&utm_medium=email\& _hsenc=p2ANqtz--j1SCv7KoBuKvtlMNmAzk2nWmKd8M3MpoDxPpQVtxn-kQ_r_Lk28vjAzzu9KbEIqa_Pm-I (accessed on 3 February 2020).

53. Miao, L.; Lehto, X.; Wei, W. The Hedonic Value of Hospitality Consumption: Evidence from Spring Break Experiences. J. Hosp. Mark. Manag. 2014, 23, 99-121. [CrossRef]

54. O'Connor, P.; Murphy, J. Research on information technology in the hospitality industry. Int. J. Hosp. Manag. 2004, 23, 473-484. [CrossRef]

55. Schmallegger, D.; Carson, D. Blogs in tourism: Changing approaches to information exchange. J. Vacat. Mark. 2008, 14, 99-110. [CrossRef]

56. Gretzel, U.; Fesenmaier, D.R. Inforamtion Tecnology: Shaping the Past, Present, and Future of Tourism. In The SAGE Handbook of Tourism Studies; Sage Publications: London, UK, 2009; pp. 558-580.

57. Fotis, J.; Buhalis, D.; Rossides, N. Social media impact on holiday travel planning: The case of the Russian and the FSU markets. Int. J. Online Mark. 2011, 1, 1-19. [CrossRef]

58. Pan, B.; MacLaurin, T.; Crotts, J.C. Travel blogs and the implications for destination marketing. J. Travel Res. 2007, 46, 35-45. [CrossRef]

59. Davis, F.D.; Bagozzi, R.P.; Warshaw, P.R. User acceptance of computer technology: A comparison of two theoretical models. Manag. Sci. 1989, 35, 982-1003. [CrossRef]

60. Moore, G.C.; Benbasat, I. Development of an instrument to measure the perceptions of adopting an information technology innovation. Inf. Syst. Res. 1991, 2, 192-222. [CrossRef]

61. Rauniar, R.; Rawski, G.; Yang, J.; Johnson, B. Technology acceptance model (TAM) and social media usage: An empirical study on Facebook. J. Enterp. Inf. Manag. 2014, 27, 6-30. [CrossRef]

62. Venkatesh, V.; Morris, M.G.; Davis, G.B.; Davis, F.D. User acceptance of information technology: Toward a unified view. MIS Quart. 2003, 27, 425-478. [CrossRef]

63. Stafford, T.F.; Stafford, M.R.; Schkade, L.L. Determining uses and gratifications for the Internet. Decis. Sci. 2004, 35, 259-288. [CrossRef]

64. Dickinger, A. The trustworthiness of online channels for experience-and goal-directed search tasks. J. Travel Res. 2011, 50, 378-391. [CrossRef]

65. Zhang, L.; Wu, L.; Mattila, A.S. Online reviews: The role of information load and peripheral factors. J. Travel Res. 2016, 55, 299-310. [CrossRef]

66. Kayahara, J.; Wellman, B. Searching for culture-High and low. J. Comput. Mediat. Commun. 2007, 12, 824-845. [CrossRef]

67. Papacharissi, Z.; Rubin, A.M. Predictors of Internet use. J. Broadcast. Electron. Media 2000, 44, 175-196. [CrossRef]

68. Mossberger, K.; Wu, Y.; Crawford, J. Connecting citizens and local governments? Social media and interactivity in major US cities. Gov. Inf. Q. 2013, 30, 351-358. [CrossRef]

69. Shao, G. Understanding the appeal of user-generated media: A uses and gratification perspective. Internet Res. 2009, 19, 7-25. [CrossRef]

70. Brown, B.; Chalmers, M. Tourism and mobile technology. In Proceedings of the Eighth Conference on European Conference on Computer Supported Cooperative Work, Helsinki, Finland, 14-18 September 2003; Kluwer Academic Publishers: Helsinki, Finland, 2003; pp. 335-354.

71. Kim, B.P.; Kim, J.; Kim, J.E. Applications of construal level theory to promotional strategies in the hotel industry. J. Travel Res. 2016, 55, 340-352. [CrossRef]

72. Baran, S.; Davis, D. Mass Communication Theory; Wadsworth: Belmont, CA, USA, 2011.

73. Sigala, M. Web 2.0 and customer involvement in new service development: A framework, cases and implications in tourism. In Social Media in Travel, Tourism and Hospitality: Theory, Practice and Cases; Ashgate Publishing: Surrey, UK, 2012 ; pp. $25-33$.

74. Ramanathan, U.; Subramanian, N.; Parrott, G. Role of social media in retail network operations and marketing to enhance customer satisfaction. Int. J. Oper. Prod. Manag. 2017, 37, 105-123. [CrossRef]

75. Rosengren, K.E. Uses and gratifications: A paradigm outlined. The uses of mass communications. Curr. Perspect. Gratif. Res. 1974, 3, 269-286. 
76. Leung, L.; Wei, R. Seeking news via the pager: An expectancy-value study. J. Broadcast. Electron. Media 1999, 43, $299-315$. [CrossRef]

77. Ferguson, D.A.; Perse, E.M. The World Wide Web as a functional alternative to television. J. Broadcast. Electron. Media 2000, 44, 155-174. [CrossRef]

78. Ko, H.; Cho, C.H.; Roberts, M.S. Internet uses and gratifications: A structural equation model of interactive advertising. J. Advert. 2005, 34, 57-70. [CrossRef]

79. Levy, M.R.; Windahl, S. Audience activity and gratifications a conceptual clarification and exploration. Commun. Res. 1984, 11, 51-78. [CrossRef]

80. Quan-Haase, A.; Young, A.L. Uses and gratifications of social media: A comparison of Facebook and instant messaging. Bull. Sci. Technol. Soc. 2010, 30, 350-361. [CrossRef]

81. Lariscy, R.W.; Tinkham, S.F.; Sweetser, K.D. Kids these days: Examining differences in political uses and gratifications, internet political participation, political information efficacy, and cynicism on the basis of age. Am. Behav. Sci. 2011, 55, 749-764. [CrossRef]

82. Han, S.; Min, J.; Lee, H. Antecedents of social presence and gratification of social connection needs in SNS. Int. J. Inf. Manag. J. Inf. Prof. 2015, 35, 459-471. [CrossRef]

83. Alonso, A.D.; O'Neill, M.; Liu, Y.; O'Shea, M. Factors driving consumer restaurant choice: An exploratory study from the Southeastern United States. J. Hosp. Mark. Manag. 2013, 22, 547-567.

84. Global Web Index. Digital in 2018 in Eastern Asia. 2018. Available online: https://www.slideshare.net/wearesocial/digital-in-20 18-in-eastern-asia-86866557 (accessed on 13 September 2020).

85. Park, Y.; Chen, J.V. Acceptance and Adoption of the Innovative Use of Smartphone. Ind. Manag. Data Syst. 2007, 107, 1349-1365. [CrossRef]

86. Kramer, R.; Modsching, M.; Hagen, K.; Gretzel, U. Behavioural Impacts of Mobile Tour Guides. In Information and Communication Technologies in Tourism 2007; Sigala, M., Mich, L., Murphy, J., Eds.; Springer: Vienna, Austria, 2007; pp. 109-118.

87. Wang, D.; Park, S.; Fesenmaier, D.R. The role of smartphones in mediating the touristic experience. J. Travel Res. 2012, 51, 371-387. [CrossRef]

88. Hwang, J.; Park, S. Social media on smartphones for restaurant decision-making process. In Information and Communication Technologies in Tourism 2015; Springer: Cham, Switzerland, 2015; pp. 269-281.

89. Creswell, J.W. Qualitative Inquiry E Research Design: Choosing among Five Approaches; Sage: Thousand Oaks, CA, USA, 2007.

90. Cullen, F. Factors influencing restaurant selection in Dublin. J. Foodserv. Bus. Res. 2005, 7, 53-85. [CrossRef]

91. KBS World. S. Korea's Smartphone Penetration Highest in the World at 95\%. 2019. Available online: http://world.kbs.co.kr/ service/news_view.htm?lang=e\&Seq_Code=142787 (accessed on 19 July 2020).

92. Saunders, M.; Lewis, P.; Thornhill, A. Research Methods for Business Students, 5th ed.; Pearson Education Limited: Harlow, MO, USA, 2010.

93. Breakwell, G.M.; Hammond, S.; Fife-Schaw, C. Research Methods in Psychology; Sage Pubilications: London, UK, 2000.

94. Braun, V.; Clarke, V. Using thematic analysis in psychology. Qual. Res. Psychol. 2006, 3, 77-101. [CrossRef]

95. Chevalier, J.A.; Mayzlin, D. The effect of word of mouth on sales: Online book reviews. Natl. Bur. Econ. Res. 2003, 43, 345-354.

96. Gretzel, U.; Yoo, K.H.; Purifoy, M. Online Travel Review Study: Role and Impact of Online Travel Reviews; Laboratory for Intelligent Systems in Tourism, Texas A\&M University: Austin, TX, USA, 2007.

97. Stafford, T.F.; Stafford, M.R. Identifying motivations for the use of commercial web sites. Inf. Resour. Manag. J. 2001, 14, 22-30. [CrossRef]

98. Williams, F.; Rice, R.E.; Rogers, E.M. Research Methods and the New Media; The Free Press: New York, NY, USA, 1988.

99. Mills, J. Consumer Attitude towards Branded Quick-Service Foods on Domestic Coach Class In-Flight Menus; University of North Texas: Denton, TX, USA, 2000.

100. Ind, N. The corporate brand. In The Corporate Brand; Palgrave Macmillan: London, UK, 1997; pp. 1-13.

101. Quintal, V.A.; Lee, J.A.; Soutar, G.N. Tourists' information search: The differential impact of risk and uncertainty avoidance. Int. J. Tour. Res. 2010, 12, 321-333. [CrossRef]

102. Power, D.J.; Phillips-Wren, G. Impact of social media and Web 2.0 on decision-making. J. Decis. Syst. 2011, 20, 249-261. [CrossRef]

103. Aronson, E.; Wilson, T.D.; Akert, A.M. Social Psychology, 6th ed.; Pearson Prentice Hall: Upper Saddle River, NJ, USA, 2007.

104. Bødker, M.; Browning, D. Beyond destinations: Exploring tourist technology design spaces through local-tourist interactions. Digit. Creat. 2012, 23, 204-224. [CrossRef]

105. Litvin, S.W.; Goldsmith, R.E.; Pan, B. Electronic word-of-mouth in hospitality and tourism management. Tour. Manag. 2008, 29, 458-468. [CrossRef]

106. Jacobsen, J.K.S.; Munar, A.M. Tourist information search and destination choice in a digital age. Tour. Manag. Perspect. 2012, 1, 39-47. [CrossRef]

107. Kietzmann, J.H.; Hermkens, K.; McCarthy, I.P.; Silvestre, B.S. Social media? Get serious! Understanding the functional building blocks of social media. Bus. Horiz. 2011, 54, 241-251. [CrossRef]

108. Pudliner, B.A. Alternative literature and tourist experience: Travel and tourist Weblogs. J. Tour. Cult. Chang. 2007, 5, 46-59. [CrossRef]

109. Kang, J.W.; Namkung, Y. Restaurant information sharing on social networking sites: Do network externalities matter? J. Tour. Res. 2015, 40, 739-763. [CrossRef] 
110. Teare, R.E. Interpreting and responding to customer needs. J. Workplace Learn. 1998, 10, 76-94. [CrossRef]

111. Crompton, J.L.; Ankomah, P.K. Choice set propositions in destination decisions. Ann. Tour. Res. 1993, 20, 461-476. [CrossRef]

112. Rokonuzzaman, M.; Harun, A.; Al-Emran, M.; Prybutok, V.R. An investigation into the link between consumer's product involvement and store loyalty: The roles of shopping value goals and information search as the mediating factors. J. Retail. Consum. Serv. 2020, 52, 101933. [CrossRef]

113. Chung, N.; Koo, C. The use of social media in travel information search. Telemat. Inform. 2015, 32, 215-229. [CrossRef]

114. Abastante, F.; Pensa, S.; Masala, E. The Process of Sharing Information in a Sustainable Development Perspective: A Web Visual Tool. In Values and Functions for Future Cities; Springer: Cham, Switzerland, 2020; pp. 339-350.

115. Liu, Z.; Park, S. What makes a useful online review? Implication for travel product websites. Tour. Manag. $2015,47,140-151$. [CrossRef]

116. Zhang, Z.; Ye, Q.; Law, R.; Li, Y. The impact of e-word-of-mouth on the online popularity of restaurants: A comparison of consumer reviews and editor reviews. Int. J. Hosp. Manag. 2010, 29, 694-700. [CrossRef]

117. Harmon-Jones, E.; Harmon-Jones, C. Cognitive dissonance theory. In Handbook of Motivation Science; Guilford Press: New York, NY, USA, 2012; pp. 71-83.

118. Bloemer, J.; De Ruyter, K. Customer loyalty in high and low involvement service settings: The moderating impact of positive emotions. J. Mark. Manag. 1999, 15, 315-330. [CrossRef]

119. Bearden, W.O.; Netemeyer, R.G.; Teel, J.E. Measurement of consumer susceptibility to interpersonal influence. J. Consum. Res. 1989, 15, 473-481. [CrossRef]

120. Hyun, Y.H.; Nam, J.H. A study on the application of the quality of smartphone app of family restaurants to TAM: A focus on a moderating effect of voluntariness. Korean Corp. Manag. Rev. 2012, 19, 149-167.

121. Independent. How Instagram Has Transformed the Restaurant Industry for Millennials. $2017 . \quad$ Available online: http:/ / www.independent.co.uk/life-style/food-and-drink/millenials-restaurant-how-choose-instagram-social-mediawhere-eat-a7677786.html (accessed on 26 July 2020).

122. Farrell, B.B. Virtualizing our mouths: The sensorium and Instagram imagery. Int. J. Food Des. 2020, 5, 113-123.

123. Bolton, R.N.; Parasuraman, A.; Hoefnagels, A.; Migchels, N.; Kabadayi, S.; Gruber, T.; Solnet, D. Understanding Generation Y and their use of social media: A review and research agenda. J. Serv. Manag. 2013, 24, 245-267. [CrossRef] 